\title{
The Information Content of Option Demand *
}

\author{
Kerstin Kehrle and Tatjana Xenia Puhan ${ }^{\dagger}$
}

This Version: September 13, 2015

\begin{abstract}
This paper combines the concept of market sidedness with excess option demand (changes in open interest) to solve the empirical challenge of separating directional from uninformed trading motives in widely available, unsigned options data. Our measure of options market sidedness persistently predicts the sign and strength of stock returns. Trading strategies conditional on the measure are highly profitable. For instance, when the measure indicates positive (negative) information, out-of-the-money calls (puts) generate returns of $27 \%$ (32\%) over roughly four weeks. Risk-adjusted returns of a long-short equity strategy yield more than $2 \%$. An increase in directionally informed demand predicts a decrease in option liquidity and increases in pricing inefficiency.
\end{abstract}

JEL-code: D82, G10, G12, G14

Keywords: Option Demand, Market Sidedness, Open Interest, Liquidity, Market Microstructure.

${ }^{*}$ We are grateful to Yakov Amihud, Torben Andersen, Snehal Banerjee, Don Chance, Anna Cieslak, Martijn Cremers, Amit Goyal, Jens Jackwerth, Ravi Jagannathan, Robert Korajczyk, Markus Leippold, Robert McDonald, Dimitry Muravyev, Stefan Nagel, Andreas Neuhierl, Mahendrarajah Nimalendran (discussant FMA 2012), Per Östberg, Dimitris Papanikolaou, Franziska J. Peter, Mitchell Petersen, Nagpurnanand Prabhala, Jörg Seidel, Nitish Sinha (discussant MFA 2012), Viktor Todorov and Alexander Wagner for helpful comments and valuable suggestions. This paper has also benefited from comments of participants at the Midwest Finance Association (MFA) Annual Meeting 2012 in New Orleans, the Swiss Society for Financial Market Research Conference (SGF) 2012 in Zurich, the Eastern Finance Association (EFA) Annual Meeting 2012 in Boston, the Financial Management Association (FMA) Meeting and Doctoral Consortium 2012 in Istanbul and 2013 in Chicago, the NCCR Finrisk Research Day 2012 and seminar participants at Kellogg School of Management, University of St.Gallen and University of Lausanne. Part of this research has been conducted while Kehrle obtained financial support of the Swiss National Centre of Competence in Research "Financial Valuation and Risk Management" (NCCR FINRISK) and Puhan was visiting research fellow at Northwestern University, Kellogg School of Management and a PhD student of the Swiss Finance Institute at the University of Zurich. Puhan also gratefully acknowledges financial support of the Swiss National Foundation and the Zell Center for Risk Research, Kellogg School of Management.

${ }^{\dagger}$ Corresponding author: University of Mannheim and Swiss Life Asset Managers, Email: tpuhan@mail.unimannheim.de. 


\section{Introduction}

A body of work in finance has documented the effects of asymmetric information on the functioning of financial markets (e.g., Kyle 1982, Grossman and Stiglitz 1980, Easley and O'Hara 1987). To financial economists and practitioners it is important to accurately determine to what extent there is informed demand in a market at a given point in time. Among other things options provide investors with leverage and therefore we expect informed trading in option markets (see Black 1975, Easley, O'Hara and Srinivas 1998). However, identifying informed demand is challenging since it has to be separated from other trading motives such as hedging and liquidity. To further complicate issues any return predictability associated with a measure of informed trading needs to be separated from other sources of return predictability that are not due to directional information, such as risk premia, volatility information or mispricing.

To deal with these challenges in a direct and easy to implement way, this paper combines the concept of market sidedness developed by Sarkar and Schwartz (2009) with excess option demand (changes in open interest) to construct a measure of options market sidedness that captures the sign and the magnitude of directional information in widely available unsigned option data..$^{1}$

The motivation for the measure is as follows: Directionally informed investors have an incentive to trade in those contracts that provide them with high leverage. This implies that the increase in the open interest of high leverage options (out-of-the money options) should be larger than the change in the open interest of low leverage options (in-the-money

\footnotetext{
${ }^{1}$ The open interest of a call or put option refers to the total number of outstanding options of a specific contract type. Since the number of outstanding option contracts is endogenous, an increase in the open interest indicates, endogenously, an excess demand for options. The existing literature has primarily used volume, option prices, bid-ask spreads or implied moments to study informed trading in option markets. However, there are many motives for trade and therefore changes in open interest have advantages over trading volume as a measure of informed demand. For example, liquidity needs and hedging demand results in volume, but may well leave the open interest unchanged (see Section 2 for a more detailed description).
} 
options). [ $^{2}$ Additionally, when informed investors have positive information we expect a higher demand for call options than for put options and vice versa in the negative information case $3^{3}$ Therefore in order to capture situations characterized by a high degree of positive information we relate changes in the open interest of out-of-the-money (OTM) call options (the most attractive options for investors with positive information) to the change in open interest of in-the-money (ITM) put option contracts. Specifically our positive information measure is the 30-day rolling correlation between the change in the open interest of OTM call options and the change in open interest of ITM put options $4^{4}$ We construct an analogous options market sidedness (OMS) measure for detecting when investors have negative information.

Intuitively, a low value of our measure implies that increases in demand for contracts that are particularly sensitive to information trading are not associated with increases in demand for contracts that are relatively insensitive to information trading. In the terminology of Sarkar and Schwartz (2009) the market is one-sided and is characterized by asymmetric information. On the other hand a high value of our measure indicates that demand for information trading sensitive contracts is also associated with increases in demand for contracts that are information insensitive, the market is two-sided and option demand is more likely driven by heterogeneous beliefs.

To examine whether options market sidedness captures informed trading, we use a dataset of all exchange traded securities at the intersection of OptionMetrics Ivy DB, the CRSP daily return files from January 1996 until December 2009 with more than 5 million observations.

We find that options market sidedness predicts the sign and the magnitude of future returns of the underlying even after controlling for a wide range of factors, including alternative

${ }^{2}$ There is usually a certain "natural" level of option contract creation and closing, for instance due to synthetic option creation for technical trading strategies that involve as a replication or closing instrument ITM options and the short side of OTM options (see e.g., Lakonishok, Lee, Pearson and Poteshman 2007).

${ }^{3}$ Despite the high probability that informed traders create new long positions we can naturally not exclude that informed traders also use different strategies. Incorporating these trades would make our results only stronger but would come at the cost of a much more complicated methodology to measure options market sidedness that is hard to use in practice.

${ }^{4}$ More formally we compute the positive information measure as $O M S^{+}=\operatorname{corr}\left(\Delta O I_{O T M}^{C}, \Delta O I_{I T M}^{P}\right)$, where $\triangle O I_{O T M}^{C}$ denote the changes in open interest of OTM call options and $\triangle O I_{I T M}^{P}$ the changes in open interest of ITM put options, respectively. 
measures of informed trading. A one standard deviation decrease in the $O M S^{+}\left(O M S^{-}\right)$ measure predicts an increase (decrease) of future returns of more than 6 basis points on a daily basis and more than $16 \%$ annually.

Trading strategies based on options market one-sidedness are highly profitable. Using options market sidedness to select option contracts yields average returns of $27 \%$ for OTM calls and $32 \%$ for OTM puts over roughly four weeks. To make sure that our results are robust to option bid-ask spreads and the implicit leverage of options we construct long-short equity portfolios based on options market one-sidedness. Our strategies generate monthly risk-adjusted returns of up to $2.22 \%$.

Further, we study options market sidedness prior and post to M\&A announcements to examine whether our measure indicates the presence of significant asymmetric information that is resolved on the announcement date. Consistent with this, we find that our measure decreases prior to the announcement and increases post announcement.

In a robustness exercise, we verify that options market one-sidedness is not related to contemporaneous and future stock liquidity and trading volume. This alleviates concerns that our results are driven by changes in liquidity of the underlying or increases in hedging demand driven by greater stock market volume.

Given that options market sidedness identifies informed trading it is likely that market makers respond to the presence of informed investors. We find that options market onesidedness is associated with future higher option bid-ask spreads. Additionally, we find that a more one-sided options market predicts violations of put-call parity. These results are consistent with market makers gradually incorporating the information in the demand of informed traders and more generally with the perspective furthered by Garleanu, Pedersen and Poteshman (2009) that demand pressure in options markets should impact prices and price efficiency.

A possible alternative explanation of our results is that investors are not informed about the returns of the underlying, but about the volatility (see e.g., Back 1993, Ni, Pan and 
Poteshman 2008, Puhan 2014). Hence, it is important to distinguish whether the excess demand is coming from directional or volatility traders. To this end we develop a measure of volatility informed trading and find that including our measure of volatility informed demand does not qualitatively affect our previous results.

The contribution of this paper is threefold. First, this paper introduces the concept of market sidedness to the options market literature and examines its predictability and information content. Second, the measure of options market sidedness that we develop has a number of desirable features: i) $O M S$ captures the part of option demand that is in excess of the demand associated with other trading motives. This solves the empirical challenge of separating informed demand from other motives of trade in the options markets; ii) the information content is volatility neutral, which is to say that the predictability associated with the measure is not due to volatility information: $:^{5}$ iii) the measure is easy to calculate and uses only widely available and low frequency data, which means it is applicable to a large set of markets beyond the US, for long time periods and it does not require any investments in new databases.$^{6}$ It also does not require a structural model that signs trades as buyer or seller initiated. Third, by using our measure of market sidedness we document the presence of informed demand in option markets that is not driven by other trading motives or other potential sources of return predictability. In particular, our work complements Pan and Poteshman (2006) who document that put-to-call volume ratios only when computed from signed options volume from detailed quote records (for most markets not widely available) contain directional information data; moreover, $O M S$ can also clearly identify the sign and the strength of the directional information and indicates when markets are driven by uninformed trading motives (high measure values). In contemporary work Johnson and So (2012) find only negative

\footnotetext{
${ }^{5}$ For example, implied volatilities or asymmetries in implied moments have been shown to predict returns (see e.g., Cremers and Weinbaum 2010, Xing, Zhang and Zhao 2010). However, these measures are not by construction or intention volatility neutral.

${ }^{6}$ While detailed option quote data is available for the US since a few years, it is not for most other markets around the world. Moreover, most investors are unlikely to buy the very expensive highly specialized US data and use only data that is widely available in databases that also provide a diversified set of different time series and hence cover the wide range of data that investors need such as Thomson Reuters, Bloomberg or FactSet.
} 
information in options trading using the option to stock volume ratio (O/S) by Roll, Schwartz and Subrahmanyam (2010) while we show that there is also substantial positive information in options trading. Moreover, they cannot differentiate between markets that are driven by uninformed motives of trade and options markets that exhibit asymmetric information. Using signed option volume, Ge, Lin and Pearson (2015) highlight that the O/S ratio, conditioned on the trade direction, predicts also positive returns. However, they use data of an exchange that is relatively small and not commonly used by institutional investors (who are most likely to be better informed and who prefer to trade in the most liquid markets) and not available for other markets. Moreover, they find no predictability for the institutional investors part of their data but they do before corporate events that are ex-ante publicly known and associated with high stock market sidedness, volatility and more option trading activities. These findings indicate that their data captures only general demand shifts in the market but does not single out the demand of informed traders. Cao, Chen and Griffin (2005) also provide evidence in support of informed trading but they focus exclusively on takeover events.

The rest of this paper is organized as follows. In Section 2, we develop our concept of options market sidedness. Section 3 details the data and investigates the sidedness of the options market around M\&A announcements. Section 4 tests the relation of options market sidedness and future stock returns. Section 5 considers trading strategies that condition on options market sidedness. In Section 6, we study the links between informed option demand and stock market trading. Section 7 considers the impact of informed option demand on liquidity levels and pricing efficiency. Finally, Section 8 concludes the paper.

\section{Measuring Options Market Sidedness}

Our measures of option market sidedness uses the fact that informed traders are most likely to build up long positions in high leverage options that consequently are the most information 
sensitive..$^{7}$ Therefore, associated with an increase in informed trading, the demand (which is proxied for by changes in open interest) for those contracts should increase relative to contracts that are less information sensitive.

We define an $O M S$ measure for positive $\left(O M S^{+}\right)$and negative $\left(O M S^{-}\right)$information trading, respectively. We compute the positive information measure $O M S^{+}$as the correlation of the change in open interest of OTM call options and the change in open interest of ITM put options. More formally, the value of the positive signal measure $O M S_{t}^{+}$is computed on each day $t$ as

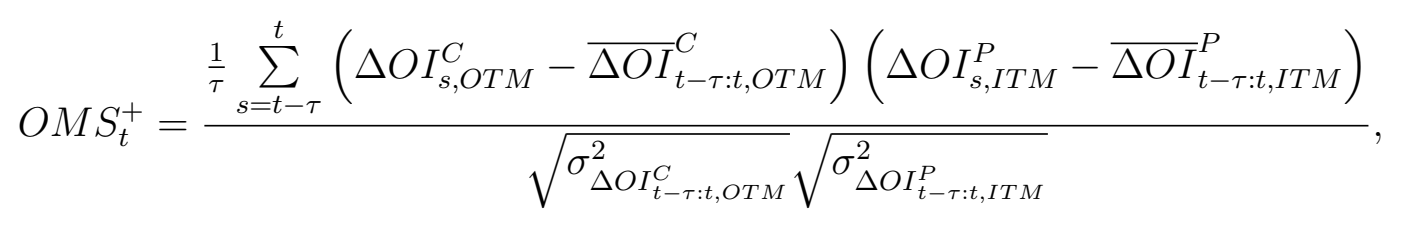

for a backward looking window of $\tau$ days ${ }^{8}$

Analogously, in case of negative information trading, the $O M S^{-}$measure is the correlation of the change in open interest of OTM put options with the change in the open interest of ITM call options.

Intuitively, when either correlation is low then increases in demand for information sensitive (out-of-the-money) contracts are not accompanied by increases in demand in less sensitive (in-the-money) contracts. In the terminology of Sarkar and Schwartz (2009) the market

\footnotetext{
${ }^{7}$ An alternative would be, for instance, to go short in the opposite contract type. However, this would expose the informed trader to much higher risk and margin requirements, which makes this trading alternative less attractive. In support of this argument, previous work, such as Garleanu et al. (2009), Pan and Poteshman (2006), Lakonishok et al. (2007), Muravyev (2013), Easley et al. (1998), Choy and Wei (2012) or Chesney et al. (2011), highlights the creation of new long positions in out-of-the-money options as main channel of information related option trading. This is supported by occasional evidence such as in Poteshman (2006) who identifies how informed investors used long out-of-the-money put options of airline companies prior to the 2001 terrorist attacks. Another example is the case of the German Commerzbank where in April 2011 in the week before a recapitalization announcement some investors took large positions in new out-of-the-money puts and realized large profits due to the post announcement stock price decline.

${ }^{8}$ In our analysis, we compute the time series of the daily $O M S$ measures for each security, for a $\tau=$ 30-day backward looking correlation between daily changes in open interest. The choice of this time window follows the idea that it would be rather counterintuitive to assume that most often options market informed trading happens at longer-term horizons (cf., Easley et al. 1998). We have also tested a decreased or expanded correlation window size within a reasonable range of days (15 to 45 days), but our results remain qualitatively unchanged.
} 
is one-sided and is characterized by asymmetric information $9^{9}$ On the other hand when the correlation is high then an increase in demand of information sensitive contracts is also associated with an increase in less information sensitive contracts 10

Our measure is also able to capture when informed investors have a particularly strong signal. In such cases there will be a particularly large demand for OTM options and in equation (1) the deviation from the mean level of demand will be large and all other things being equal the correlation will take lower values.

There are three advantages of using a correlation over alternative measures such as a simple ratio, a difference in mean values or simple changes in open interest. First, the correlation is standardized by the variation of the variables (so in a simple sense we control for volatility). Second, the variation is benchmarked against its own mean, implying that we are considering above average deviations in open interest. Third, a correlation considers whether the standardizes above average excess demand in OTM options in the estimation window coincides with above average excess demand of ITM options. While ratios and differences in means can also be formed using standardized variables and with averages across certain time windows, the ability to capture the comovement of two variables over time is unique to a correlation measure.

We base our measure on changes in open interest since this arguably has a stronger connection with informed option demand. Table 1 illustrates the effect on volume and open interest of a transaction between Buyer A and Seller B.

In case 1 buyer $\mathrm{A}$ wants to buy a contract to open a new position and seller $\mathrm{B}$ has to create a new position in order to cater to the demand, the open interest increases and there is positive trading volume. Alternatively, in case 2, if buyer A enters the options market to buy a contract to close a position, and seller B sells this contract, thereby closing a previously held position, there is a decrease of open interest along with positive option trading volume.

\footnotetext{
${ }^{9}$ Due to technical trading strategies, liquidity needs or hedging demand, there is always a certain natural level of demand and supply across contract types.

10 An alternative measure would relate the open interest OTM calls to OTM puts, but this measure would not be able to distinguish the sign of the information.
} 
Table 1: $\triangle O I$ vs. Volume. The table summarizes all possible four combinations for the opening and closing of option positions between some buyer A and some seller B. The column named $\triangle O I$ indicates the potential changes in the open interest related to the trading combination and their sign. The column Volume reports whether there is a positive trading volume.

\begin{tabular}{lcccc}
\hline & Buyer A & Seller B & $\Delta O I$ & Volume \\
\hline 1: & buy to open & sell to open & $>0$ & $>0$ \\
2: & buy to close & sell to close & $<0$ & $>0$ \\
3: & buy to open & sell to close & $=0$ & $>0$ \\
4: & buy to close & sell to open & $=0$ & $>0$ \\
\hline
\end{tabular}

While both case 1 and case 2 result in a change in the open interest it is likely that case 1 is going to contain the most information. Intuitively, the demand from informed investors is going to result in the creation of new contracts and this is supported by the findings of $\mathrm{Ni}$ et al. (2008), Pan and Poteshman (2006), Muravyev (2013), Lakonishok et al. (2007), Bollen and Whaley (2004), Easley et al. (1998), Garleanu et al. (2009) or Chesney et al. (2011). Put differently, for case 2 to contain information this requires that the informed investor and the market maker to have open positions in this option, which is on average relatively unlikely given that the signal is truly informative.

Furthermore, in cases 3 and 4, we observe positive trading volume, however, since in both cases one party opens and another party closes a position, there is no change in the open interest even though we observe trading volume. This illustrates why using trading volume is different from considering excess option demand and arguably why it is a more noisy measure of informed demand 11

\section{Data and Descriptive Analysis}

In this section we describe the data selection, summarize the data and provide evidence about options market sidedness around M\&A announcement dates.

11 The difference between changes in open interest and volume is also evident in the unconditional correlation of OTM option changes in open interest and trading volume, which is only 0.1 for call options and 0.08 for put options, respectively. Consistent with this, the unconditional correlation of the $O M S$ measure computed with changes in open interest and an $O M S$ measure computed with trading volume is very low and only 0.118 and 0.124 for $O M S^{+}$and $O M S^{-}$, respectively. 


\subsection{Data and Summary Statistics}

Our daily options market data consist of all American option contracts for all available US stocks at the intersection of OptionMetrics Ivy DB and CRSP stock market data described below ${ }^{12}$ The options have a standard settlement (i.e., per contract 100 shares of the underlying are delivered at exercise). The sample period is January 1996 until December 2009. We exclude option contracts with a maturity of more than 250 days and observations with no or zero open interest to exclude options without liquidity (cf., Driessen et al. 2009). We merge this data with the daily stock market data from the CRSP NYSE/AMEX/NASDAQ return files. Only securities from the merged CRSP and Compustat database are in the sample. As common practice in the literature we exclude stocks with a return history of less than 24 consecutive months to ensure the reliability of our regression results. We exclude observations at the $99 \%$ and $1 \%$ level with respect to $B M$ and we exclude stocks with a stock price below 1USD or with a return above $80 \%$ or below $-80 \%$ [13 After applying these filter rules, 4,155 firms remain in our final sample and 35,349 call and put contracts resulting in more than 5 million daily observations for each variable.

We then sort all option contracts of each stock in moneyness categories in order to aggregate the option variables of interest for each moneyness group. Similar to e.g. Chakravarty et al. (2004), Lakonishok et al. (2007) or Xing et al. (2010) we define the moneyness range for options as the ratio of the strike price $K$ and the stock price $S$ (for call options $\frac{K}{S}$ and for put options $\left.\frac{S}{K}\right) !_{4}^{14}$ For OTM options the respective ratio is larger than 1.05 and for ITM options it is smaller than 0.95. Accordingly, ATM options have a moneyness range of 0.95-1.05. For the OTM part of our OMS measure we consider those contracts that are OTM on at least 2

\footnotetext{
12 OptionMetrics Ivy DB is a comprehensive data set with information on the entire US equity options market.

13 The annual book-to-market ratio on day $t$ is given by the previous year's end-of-year book equity divided by the corresponding year's market equity (BM) (see Daniel and Titman 2006).

14 To test the robustness of our results with respect to our moneyness definition we also compute the moneyness ratio as $\ln \left(\frac{K}{F} / I V_{A T M} \sqrt{T}\right)$, where $F$ is the futures price and $I V_{A T M}$ is the implied volatility of ATM options of the respective stock. Our results qualitatively do not change if we use this ratio.
} 
out of 5 days during the fourth week before the maturity date. 15

After selecting options into moneyness categories we aggregate the daily open interest for each moneyness category, i.e., ITM Call, ITM Put, ATM Call, ATM Put, OTM Call, and OTM Put. ${ }^{16}$ For each stock $k$ we compute the median of the open interest of option contracts in a moneyness category ${ }^{17}{ }^{18}$ The daily change in open interest is calculated separately for call and put options within a moneyness category and subsequently used to compute our measures of options market sidedness.

Table 2 provides summary statistics for the $O M S^{+}$and $O M S^{-}$. The overall number of observations is roughly 5 million for $O M S^{+}$and $O M S^{-}$.

\section{INSERT TABLE 2 ABOUT HERE}

$O M S^{+}$and $O M S^{-}$are on average positively valued (0.43 and 0.46$)$ and the $25 \%$ quantile is also positive (0.11 and 0.16 ), which is to be expected since directionally informed demand is neither permanent nor frequent; hence it would be surprising to observe a large fraction of negative $O M S$ values.

As control variables we construct alternative information measures the daily option volume and option bid-ask spread. We aggregate the number of traded contracts $\left(V O L_{t, m}^{j}\right)$ for each stock as the median of the volume for call and put option $(j=\{C, P\})$ separately in each moneyness category $m$. Because the distribution of $V O L_{t, m}^{j}$ is right-skewed we use in our regressions $S V O L_{t, m}^{j}$, i.e., the square root of daily volume for call or put options 19

Similarly, we also control for bid-ask spreads. $S P R E A D_{t, m}^{j}$ and $S P R E A D_{t, m}^{j}$ denotes the

15 To give an example: If on October 19 the December 19 contract is OTM we would not use it to compute our measure going forward because the time to maturity is still too distant. If the contract is OTM on November 20 and 21, we would start using it after November 21 to compute our measure going forward. Our selection rule follows the intuition that it is rather unlikely that investors obtain signals several months in advance. We have also considered alternative OTM day selection rules up to two weeks before maturity and with more or less minimum OTM days; our results are qualitatively unchanged.

16 The daily preliminary open interest is reported at the end of each trading day and the final official data is released on the following morning.

17 We use the median in order to mitigate the impact of potential outliers.

${ }^{18}$ In what follows, we omit for reasons of simplicity the index $k$. Nevertheless, all measures and variables are computed for each single underlying stock.

19 The square root of the volume is useful to normalize the variable. 
median daily relative bid-ask spread of call or put options in different moneyness categories $m$.

Table 2 provides also summary statistics for option spreads and volume. The spread size varies substantially with the moneyness ranges, the mean of the spread is roughly 1 for the OTM options $\left(S P R E A D_{O T M}^{C}, S P R E A D_{O T M}^{P}\right)$ and roughly 0.1 for the ITM options $\left(S P R E A D_{I T M}^{C}, S P R E A D_{I T M}^{P}\right)$. This is in accordance with the well-known fact that it is more expensive to trade in OTM options. Nevertheless, OTM options are usually the most actively traded type of options, which is also the case in our sample. The normalized options trading volume is relatively higher for OTM options $\left(S V O L_{O T M}^{C}, S V O L_{O T M}^{P}\right)$. However, the difference between the trading volume of OTM and ITM options is not extremely large, for instance for call options $S V O L_{O T M}^{C}$ is 4.4 and $S V O L_{I T M}^{C}$ is 3.5. This is important since we correlate the ITM options with the OTM options, in order to capture the information trading related excess demand. If the level of trading activities in ITM options was extremely lower than for OTM options, it would be difficult to identify information in OTM excess option demand.

Other variables that we extract from CRSP are the closing price, high and low prices, shares outstanding and the volume as the total number of traded shares of stock. We also use a proxy for the underlying's daily realized volatility, which we define as in Ni et al. (2008) as 10,000 times the difference of the underlying stock's intraday high and low prices divided by the closing stock price $(R V)$. Market equity is defined as the price of a stock on day $t$ multiplied by the shares outstanding. The logarithm of market equity is used to measure firm size $(S I Z E)$. We compute momentum $(M O M)$ as the 60 days backward looking cumulative return and long-term volatility $(S T D)$ as the square root of the averaged cumulative squared returns. Also from CRSP we obtain a value weighted NYSE/AMEX index with dividends as a proxy for monthly market returns. From all returns of the individual stocks and the market index we subtract the average one month risk free rate from the Fama risk free rates file as provided by CRSP. We obtain monthly market betas as in Easley et al. (2002) and denote the individual stock market beta as BETA. In the daily cross-sectional regressions we include 
the stock's previous month's market portfolio betas to control for the single stock's market risk exposure. Descriptive statistics for BETA, SIZE, BM, RV, MOM and STD are in Table 2. As a proxy for stock market illiquidity, we compute the Amihud (2002) illiquidity measure in basis points as $\left.I L L I Q_{\text {Amihud }}=1 \times 10^{10} *|R E T|\right) /$ Volume, where Volume is the daily trading volume of a stock. We extract annual fiscal year-end book equity values from the COMPUSTAT data base.

Earnings announcement dates $(E A D)$ are obtained from the I/B/E/S Database.

\subsection{Information in Option Demand around High Information Events}

In this section, we use M\&A announcements to validate that our measure captures informed demand. Prior to M\&A announcements there is arguably a significant amount of asymmetric information that is resolved at announcement ${ }^{20}$ This implies that we expect our measure to decrease in the pre-announcement period (as there is an increase in informed demand) and post-announcement we expect this decrease to be reversed. To ensure that our measure captures directional information we pair $O M S^{+}\left(O M S^{-}\right)$with events with positive (negative) announcement day returns.

The M\&A data is from the SDC Platinum database and we follow Schwert (1996) in defining the announcement date as the first day when an official bid becomes known. We exclude firms that have received another bid in the same year. We calculate the cumulative change in $O M S^{+}$ and $O M S^{-}$from 7 days before the announcement day $t=0$. Figure 11 describes the change in the $O M S$ measures over this period in the positive (upper subfigure) and negative (lower subfigure) informed demand case ${ }^{21}$ The plot of the cumulative changes for the M\&A dates is marked in green and with dots. As a benchmark we also plot (in red and with triangles) the average $O M S$ measure changes of firms not making announcement. The figure illustrates

\footnotetext{
20 This is different from for instance earnings announcements that are publicly known dates and that are associated with two-sided stock markets, significant increases in option trading volumes and volatility.

${ }^{21}$ We choose a 7-day window before the high information date as a reasonable time window before a high information event where we would expect the major demand of investors with private information related to the event. However, our results do not qualitatively change if we extend the time window within a sensible range.
} 
that our as predicted, directly before the M\&A announcement, i.e., on the evening before the announcement day, we observe that the cumulative change in $O M S^{+}$exhibits 27 times lower values than the benchmark case and for $O M S^{-}$it is more than 30 times lower.

Moreover, there is a significant reincrease in the measures ex post the M\&A announcement, which reflects that once the news become public and options markets become more two-sided.

\section{INSERT FIGURE 1 ABOUT HERE}

To verify the robustness of the M\&A announcement date results, we also consider days with large return movements, which arguably are also events of high information. In the positive information case we define high return events as days where the return is above the average daily return within the subsample of days with positive returns and in the negative information case we consider days where the return is below the average return on a negative return day. The plot of the cumulative $O M S$ measure changes around the extreme return dates is marked in blue and with diamonds and confirms the patterns that we find for the M\&A announcement dates.

\section{Option Market Sidedness and Future Stock Returns}

In this section, we examine the relationship between options market sidedness and future stock returns. In particular, we investigate whether an increase in options market one-sidedness, i.e., lower $O M S^{+}\left(O M S^{-}\right)$values, predicts higher (lower) stock returns.

\subsection{Option Market Sidedness Sorted Stock Portfolio Returns}

Panel A of Table 3 reports daily mean stock excess returns for equity portfolios that are sorted into different groups according to the firm individual $O M S$ measure value. The $O M S$ measure is a correlation and thus it takes values on a scale from -1 to +1 . To form stock

portfolio groups, we set the portfolio break points at 0.2 interval steps of the $O M S_{t-1}^{+}$and 
$O M S_{t-1}^{-}$measure, respectively, resulting in 10 portfolios.22 We compute the mean excess stock returns on each day $t$ of these 10 portfolios across our sample firms. ${ }^{23}$ In Panel A of Table 3 we observe that the $O M S$ groups vary in their size from roughly 25,000 observations to more than 1 million. The relatively smaller (but still quite sizeable) number of very low $O M S$ is intuitive since negative $O M S$ values reflect option demand induced by extremely strong information signals. It is also more likely that private information trading is reflected in a gradual decrease of the measure.

\section{INSERT TABLE 3 ABOUT HERE}

Consistent with option market one-sidedness being an indicator of asymmetric information, we find for lower values of the $O M S$ measure (i.e., the options demand is more one-sided) higher future equity portfolio returns if we sort according to the positive information measure and lower future returns for the negative information case. The average daily return difference (0.12 for $O M S^{+}$and -0.11 for $O M S^{-}$) between the portfolio that is associated with the lowest $O M S$ values (Low) and the portfolio of stocks with the highest $O M S$ values (High) shows that the average daily return spread from low to high $O M S$ values is highly significantly different from zero and exhibits also the right sign. If we compare the lowest portfolio (1) with portfolio (9) the economic magnitude of the return difference is even larger.

It is evident from Table 3 that the relation between the lagged $O M S$ measures and stock returns exhibits a nonlinear pattern. The returns decrease (increase) nonlinearly with an increase in $O M S_{t-1}^{+}\left(O M S_{t-1}^{-}\right)$. This return pattern reflects substantial price adjustments for extremely low $O M S$ values and indicates that the $O M S$ measure is able to indicate when the information signal is strong, informed investors trade aggressively and take larger positions. Analogously, these findings hold but with reversed signs for the equity portfolio returns of the

${ }^{22}$ An alternative way of forming portfolios is to sort stocks into return decile portfolios and then compute their average $O M S_{t-1}$ values. However, for us it is more interesting how future stock returns line up with the distribution of the current $O M S$ measures, similar to the standard practice in asset pricing to sort portfolios according to certain characteristics such as size or BM and to compare returns across those portfolios.

${ }^{23}$ We use stock returns that are in excess of the risk-free rate. If we risk-adjust them with respect to the Fama-French and Carhart factors, the quality of the results remains unchanged. 
$O M S_{t-1}^{-}$sorted portfolios. However, even with this reincrease in returns, the return spreads between the lowest and highest portfolios are still highly significantly different from zero.

In Panel B of Table 3 , we compute an $O M S$ measure using option trading volume $\left(\mathrm{VolOMS} \mathrm{S}^{+}\right.$ and $\mathrm{VolOM} \mathrm{S}^{-}$) instead of changes in open interest. The results show that a volume based $O M S$ measure is not successful in identifying when markets are driven by asymmetric information and when by heterogenous beliefs. Sorting according to $\operatorname{VolOM} S^{+}$results in an insignificant return spread between the Low and the High VolOMS group and and for $\operatorname{VolOM} S^{-}$the spread is significant but with the wrong sign (the returns in the Low portfolio have to be lower than the returns in the High portfolio). Moreover, we observe that almost all $\operatorname{VolOMS}$ value observations are $\geq 0$, which further supports the notion that for trading volume it is rather difficult to differentiate between informed demand and other trading motives.

\subsection{Cross-Sectional Stock Return Predictions}

We use Fama and MacBeth (1973) (FMB) regressions to test the relation of future individual stock returns and the directional $O M S$ measure ${ }^{24}$ The empirical specification reads as,

$$
R E T_{t}=\beta_{0}+\beta_{1} O M S_{t-1}^{+}+\beta_{2} O M S_{t-1}^{-}+\mathbf{b C}_{t}+\epsilon_{t}
$$

where $R E T_{t}$ is the daily stock return in excess of the risk free rate. ${ }^{25} \beta_{0}, \beta_{1}$ and $\beta_{2}$ denote the coefficients of the intercept, the $O M S_{t-1}^{+}$and the $O M S_{t-1}^{-}$measure at day $t-1$. Further, we include in (2) $\mathbf{C}_{\mathbf{t}}$, which is a vector of control variables such as firm size, book-to-market ratio, market returns, lagged stock returns, long-term past stock returns, long-term past stock return volatility and option volume. The corresponding coefficient vector is $\mathbf{b}$.

We conjecture a negative (positive) sign for $\beta_{1}\left(\beta_{2}\right)$, reflecting that $O M S_{t-1}^{+}\left(O M S_{t-1}^{-}\right)$

\footnotetext{
${ }^{24}$ We choose daily windows for the entire empirical part. Obviously, informative signals can persist intradaily, for one or two days or for longer periods, depending on the nature of the signal.

${ }^{25}$ If we risk adjust the returns with regard to the Fama-French and Carhart factors, the quality of the results remains unchanged.
} 
takes lower values due to the positively (negatively) informed demand and predicts higher (lower) returns in the future.

Table 4 reports the main FMB-regression results with stock returns as dependent variable ${ }^{26}$ We use percentage returns in the regressions and can therefore interpret the estimated coefficients directly as a percentage change in returns the day after e.g. the directional $O M S$ measure drops from zero to minus one.

\section{INSERT TABLE 4 ABOUT HERE}

In column (I), we validate the predictive power of the directional $O M S$ measure, firstly without including any of the control variables. The coefficient of the $O M S_{t-1}^{+}$measure is negative and statistically significant. This supports our hypothesis that OTM call option excess demand indicates positive information trading. Our results imply that a drop of the $O M S_{t-1}^{+}$measure from zero to minus one is associated with an increase of the returns on the next day by 16 basis points (or an annualized $49 \%$ increase in returns). If we compute the standardized coefficient we obtain for a one standard deviation decrease in $O M S^{+}$a 6.4 basis points increase in the next day's return (or an annualized 16\%).

The coefficient of the $O M S_{t-1}^{-}$measure is as expected positive and significant. The decrease in the return on the next day that is implied by an $O M S^{-}$measure change from zero to minus one is 15 basis points or 6.1 basis points for the standardized coefficient.

The t-statistics of our measures are smaller than in Pan and Poteshman (2006) (who use private data) but much larger than those generally found in this literature.

In all columns we include squared terms of our $O M S$ measures. The squared $O M S$ measure coefficients always exhibit the opposite sign to the respective original measure indicating that a negative change in the directional $O M S$ that is close to minus one, i.e., the information is stronger and options market are more one-sidedness, is associated with a relatively larger

\footnotetext{
${ }^{26}$ To save space we omit the results for the stock related control variables in the table. They are available
} on request. 
return movement than a negative change in $O M S$ close to zero ${ }^{27}$

In column (II) we also add the contemporaneous $O M S^{+}$and $O M S^{-}$measures in order to validate the predictive power of the lagged $O M S$ variables. The testable prediction for this specification is that the contemporaneous term exhibits the opposite coefficient with respect to the coefficients of the lagged $O M S$ measures since at time $t$ the information becomes public and options markets exhibit less information asymmetry, i.e., the $O M S$ measures take higher values. Furthermore, the results for the lagged coefficients should qualitatively not be affected by including the contemporaneous term. This is exactly what we find.

In column (III), we control in addition for various other variables related to market risk, firm characteristics, liquidity and volatility. Our results are not affected by these controls.

Our $O M S$ measure has two key components. First, the measure is based on changes in open interest to capture demand. In Section 4.1, Table 3 we show that performs better than volume as informed demand indicator. Second, by relating the demand for information sensitive contracts to insensitive contracts the measure separates informed demand from other trading motives. Therefore, we focus now on verifying that our measure of option market sidedness is superior to other potential measures that we could compute from changes in open interest.

In column (IV) we start with running a horse-race between the call-to-put-ratio $(C P-$ RATIO), which we compute for each stock as the ratio of daily changes in open interest in call and in put option contracts minus one. As expected, we find that high values of the $C P-R A T I O$ indicate bullish sentiment and high future returns. However, including the $C P-R A T I O$ does not change our findings concerning the $O M S$ measures and although statistically significant the statistical and economic significance of the $C P-R A T I O$ is lower ${ }^{28}$ In terms of economic significance, the standardized coefficient of the $C P-R A T I O$ is only

\footnotetext{
${ }^{27}$ Notably, excluding those stocks within the lowest $25 \%$ quantile in terms of option volume does not affect the quality of our results. We have also tested whether our results still hold if we run the above daily regressions for each year in our sample separately. We find that the results are in almost all years qualitatively the same as for the whole sample.

28 The unconditional correlation between the $C P-R A T I O$ and the $O M S$ measures is -0.02 for the $O M S^{+}$ and 0.002 for the $O M S^{-}$measure, respectively. If we construct the ratio using trading volume, the unconditional correlation between the ratio and the $O M S$ variables is virtually zero.
} 
one third as large as the $O M S$ measures' (i.e., 2 basis points vs. 6 basis points on a daily basis) 2930

In column $(\mathrm{V})$, we include two alternative open interest based variables, $\overline{\Delta O I}_{O T M, t-1}^{C}$ and $\overline{\Delta O I}_{O T M, t-1}^{P}$. The variables are the means of the changes in the open interest of OTM call and put options in a 30-day rolling window. The results show that the simple average level effects of both excess demand variables have weak statistical and economical predictive power (standardizing the coefficients yields a change in the next day's returns of $1.8(-3)$ bps for a one standard deviation change in $\left.\overline{\Delta O I}_{O T M, t-1}^{C}\left(\overline{\Delta O I}_{O T M, t-1}^{P}\right)\right)$. Including these variables does also not affect the coefficients of the $O M S$ variables ${ }^{31}$ Thus, basic levels are not sufficient, illustrating that relating OTM and ITM contracts is necessary to differentiate between different trading motives that might change the open interest.

In column (VI) we add the difference between $\overline{\Delta O I}_{O T M, t-1}^{C}$ and $\overline{\Delta O I}_{O T M, t-1}^{P}$, which is another alternative open interest based measure. Intuitively, the difference in both means might become larger in case of positive informed trading and should exhibit large negative values in case of negative information trading, yielding a positive regression coefficient. However, the coefficient is negative, which indicates that this measure fails completely to differentiate between changes in the open interest due to uninformed or informed reasons.

A potential alternative explanation of our results could be that investors might have information about the volatility of future returns $(R V) \cdot 32$ We control for volatility trading

29 Using alternatively for instance the simple call open interest, divided by the simple put open interest, does not affect our results. Using a ratio of standardized changes in open interest does also qualitatively not affect our results. All results are available on request.

${ }^{30}$ In unreported results, we include, as a control for market risk premia related option trading as explanation to the patterns that we find. More specifically, we regress the individual stock returns on directional $O M S$ measures for positive and negative information trading at the index level (S\&P500 equity index options). Since it is very unlikely that informed traders exploit directional signals at the index level, a significant negative (positive) coefficient for the positive (negative) information measure on the index level in the return regressions would indicate that $O M S$ also picks up market risk premia (e.g., Puhan 2014, Pan and Poteshman 2006). However, we find only insignificant results for the coefficient of the index $O M S$ measures.

31 The unconditional correlation between the $\overline{\Delta O I}_{O T M, t-1}^{C}$ and $O M S^{+}$is -0.04 and between $\overline{\Delta O I}_{O T M, t-1}^{P}$ and $O M S^{-}$the correlation is -0.06 . If we construct the 30 day averages with levels or changes in trading volume, the unconditional correlations are virtually zero.

32 Previous work of e.g. Back (1993), Ni et al. (2008) and Puhan (2014) show that the options market contains information on the future volatility of stock or index returns. 
by including a measure of volatility informed demand that we call $O M S^{\sigma}$. We measure the option demand of the volatility traders by selecting all closest to maturity ATM call and put option pairs that could be part of a straddle strategy and correlate their change in open interest for a 30-day backward looking window. More formally the measure reads as $O M S^{\sigma}=\operatorname{corr}\left(\Delta O I_{A T M}^{C}, \Delta O I_{A T M}^{P}\right)$, where $\Delta O I_{A T M}^{C}$ denote the changes in open interest of ATM call options and $\Delta O I_{A T M}^{P}$ the changes in open interest of ATM put options, respectively 33 This measure of volatility informed option demand takes higher values whenever the open interest of both sides of the ATM option pair exhibits a stronger comovement, indicating volatility information related trading.

In Appendix 2 we verify that $O M S^{\sigma}$ is indeed informative about future stock price volatility following Ni et al. (2008); we also show that before earnings announcement dates, which are known to be preceded by two-sided stock markets (Sarkar and Schwartz 2009) and followed by an increase in volatility (e.g., Ni et al. 2008, Beaver 1968), the predictive power of $O M S^{\sigma}$ for future $R V$ increases. In Appendix 2 we also show that $O M S^{+}$and $O M S^{-}$have no predictive power for future $R V$ neither in normal times nor before earnings announcement dates.

We start by adding in column (VII) of Table 4 the $O M S^{\sigma}$ measure. $O M S^{\sigma}$ does not significantly predict stock returns. Furthermore, the results for the directional OMS measures are unaffected by including $O M S^{\sigma}$, showing that the predictive power of $O M S^{+}$and $O M S^{-}$ is not associated with volatility informed trading.

Finally in column (VIII), we control for earnings announcement dates, as times of heterogenous beliefs and an increased future volatility, by interacting the $O M S$ measure with a dummy $(E A D)$ that is equal to 1 if the date is an announcement date. If the predictive power of the measure for stock returns is indeed due to directional information trading, the predictive power should not increase before an earnings announcement day. Consistent with this, we find that $O M S^{+} \cdot E A D$ and $O M S^{-} \cdot E A D$ exhibit insignificant coefficients and the

\footnotetext{
${ }^{33}$ Since the option Vega is greatest for at-the-money (ATM) options and volatility traders do not know the direction of the future stock return movement, we make the common assumption that volatility informed traders take straddle positions in ATM options in order to exploit their information (cf., Ni et al. 2008).
} 
results for the non-interacted $O M S$ terms remain unaffected. This supports that $O M S^{+}$and $O M S^{-}$indeed capture directional information.

In order to examine more closely the information content of option demand for future stock returns, we investigate next, similar to Pan and Poteshman (2006), the predictability horizon of the $O M S$ measure. If our measures indeed pick up persistent patterns of directional information in option demand, we would expect the predictability to persist for several days and not to revert too quickly. So we extend the predictability horizon of $O M S^{+}$and $O M S^{-}$ respectively up to 20 trading days. Figure 2 plots the slope coefficients of $O M S^{+}$on the left-hand side and the slope coefficients of $O M S^{-}$on the right-hand side. The dashed lines are the $95 \%$ confidence-intervals.

\section{INSERT FIGURE 2 ABOUT HERE}

The plots show that the predictability is robust and relatively strong during the first three weeks in the positive information case and during the first two weeks in the negative in-

formation case. Subsequently, the predictability of $O M S^{+}$and $O M S^{-}$decays further and looses its economical and statistical significance. These results provide strong support for our hypothesis that option market one-sidedness indicates directional informed trading.

In Appendix 3 we investigate the information flows between the options market sidedness measures and stock returns. We test in a trivariate VAR system whether stock price changes Granger cause options market one- or two-sidedness and vice versa. We find that the information in the $O M S$ measures is first reflected in the options market and moves only slowly into the stock market, which is consistent with the persistent predictive power of the $O M S$ measures. Our analysis also reveals that stock market news trigger options market two-sidedness, i.e., heterogeneous beliefs. 


\subsection{Sorts on Firm Characteristics}

In the literature on stock and options market informed trading, several firm characteristics such as size are associated with an increased probability of informed trading in the options market. For instance, Easley et al. (1998) show that informed traders more likely trade in the options market if the underlying is smaller and less liquid and Ni et al. (2008) show that this is the case for higher volatility stocks.

In order to study the cross-sectional implications of excess option demand, we build quartile portfolios of stocks that are sorted according to the size or volatility of a firm at the end of the previous year. Then, we run the regression in (2) for each quartile portfolio ${ }^{34}$ The expected signs of the coefficients for the $O M S$ measures are as in the above for regression model (2), however, we expect the absolute size of the coefficient to be larger for smaller and for higher volatility firms.

The regression results for portfolios sorted according to a firm's size or volatility are reported in Table 5. As in the previous regressions we control for several other factors such as past cumulated returns, lagged return, past standard deviation of the stock returns, option volume or market risk sensitivity.

\section{INSERT TABLE [ ABOUT HERE}

In the left part of Table 5, the coefficients of the call and put options market sidedness measure $\left(O M S_{t-1}^{+}\right.$and $\left.O M S_{t-1}^{-}\right)$are as expected significantly negative and positive, respectively. In line with the predictions from Easley et al. (1998) there is a stronger relationship of private information trading and stock returns for smaller firms.

In the right part of Table 5, we consider cross-sectional regressions of the excess returns of quartile portfolios that are sorted according to the yearly return standard deviation. The coefficients of the $O M S$ measure clearly increase in absolute terms with an increasing stock

\footnotetext{
34 We also ran regressions for stock trading volume sorted quartile portfolio excess returns. However, the intuition for this sorting variable and the regression results are very similar to the size sorted portfolios. Therefore, we do not report them for reasons of brevity. They are available on request.
} 
return volatility. These results confirm that informed traders are more likely to trade in higher volatility stocks.

Furthermore, we observe that in both sorting exercises, the results for the other portfolios, i.e., larger and less volatile firms, still remain significant, indicating that the predictive power of the $O M S$ measures not restricted to small or highly volatile firms ${ }^{35}$

\section{$5 \quad$ Trading Strategies}

In this section, we assess the profitability of trading strategies based on our OMS measures. We consider strategies based on options and the underlying. We use simple trading rules since our primary aim is not to find a return maximizing investment strategy but to assess the economic significance of the predictive relation between options market sidedness and stock returns.

Lower values of the $O M S$ measures indicate an increase in option market one-sidedness. More specifically, lower values of $O M S^{+}$indicate higher future returns and lower values of $O M S^{-}$signal lower future returns. Hence, we choose low levels of the $O M S$ measure as positive or negative information trading signals. The trading signals are values of the $O M S$ measures that are at or below 036

The general trading procedure (no matter whether it is an option or an equity based strategy) is as follows; whenever the trader obtains for the first time a trading signal in a time window that starts three weeks before maturity and ends fours days before the maturity date, the investor trades on the subsequent day. Since the open interest is reported in the evening, the trader can obtain the signal only after the exchange closes. The last trade is possible on three days before maturity. In order to limit the portfolio turnover, we allow for trading

35 Another indication for the broad scope of the $O M S$ measures is that excluding the observations in the lowest option volume quantile also does not change our results.

${ }^{36}$ We have tested all strategies using different trading signal thresholds partly reported in Appendix 4. The trading returns increase, the lower we require $O M S$ to be, however, this comes at the cost of fewer observations and a higher standard deviation in the returns to the trading strategies. Therefore, we choose in what follows a relatively conservative threshold value. 
only at the first time a signal arrives. All positions are sold simultaneously two days before maturity 37

In the first trading strategy we buy OTM call options in case of positive and OTM put options in case of negative information as indicated by the $O M S$ based trading signal. This strategy implements the opening of new long positions that previous studies as well as our paper associate most importantly with informed trading ${ }^{38}$

For the second strategy, we buy those stocks, for which we obtain positive information signals from $\mathrm{OMS}^{+}$and sell those stocks, for which we obtain a negative information trading signal. Even though we are interested in informed trading in options markets, we add this equity based strategy to alleviate concerns about option bid-ask spreads $39 \sqrt{40}$

In the third strategy, we form delta-hedged portfolios in order to verify that our trading strategy results are not heavily biased by a higher moment risk compensation. Delta-hedging shuts off the directional exposure of the underlying by short-selling or buying delta shares of the underlying contract in the long call or long put strategy, respectively. Therefore, if the returns from the above trading strategies are not largely driven by higher moment risk we would expect very low returns or returns that are insignificantly different from zero.

To compute the strategy returns, we form portfolio groups with respect to an option's moneyness and time to maturity at the investment date. The moneyness groups are sorted similar as in e.g. Chakravarty et al. (2004), Lakonishok et al. (2007) or Xing et al. (2010), that is according to the ratio of the strike price $K$ and the stock price $S$. For call options we use $\frac{K}{S}$ and for put options we use $\frac{S}{K}$. Clearly, a higher leverage makes an option investment more attractive for an informed investor. However, the increasing transaction costs with higher

\footnotetext{
37 Note that for different ranges of trading windows we obtain qualitatively similar or even stronger results.

${ }^{38}$ For example, in the evening of 01/02/2006 a trader, who follows the first trading strategy, receives a positive signal, e.g., the $O M S^{+}$takes values that are $\leq 0$, for Apple Inc.. The next day he buys an OTM call option with expiration date $01 / 21 / 2006$. He sells the option on the Thursday (i.e., 01/19/2006) before the option expires.

${ }^{39}$ We use the stock closing price as reported in CRSP for the day after the trading signal.

${ }^{40}$ In Appendix 4 we provide results for trading strategies that account for different levels of transaction costs at different trading thresholds. The results show that our results are fairly robust to including transaction costs.
} 
leverage (i.e. moneyness) create a trade-off between potentially higher gains and potentially higher costs. Therefore, we limit our trading strategy to option contracts with a moneyness of up to and including 1.3. The time to maturity groups are formed according to the temporal distance between the point in time when the investor receives the trading signal and the maturity date ${ }^{41}$

Table 6 reports the trading strategy results.

\section{INSERT TABLE 6 ABOUT HERE}

On average in each trading round we are invested in option contracts for 430 different stocks due to positive $O M S$ based trading signals and in option contracts for 415 different stocks due to negative signals depending on the strategy type. The size of the investment universe is not only interesting from a risk perspective but also from the point of view of an investor who would like to dedicate a notable amount of money into a strategy that follows option market one-sidedness.

The returns in Panel A increase with moneyness and time to maturity. The average portfolio returns for the different maturity and moneyness groups for the call option portfolio range between roughly $9 \%$ and $27 \%$ per trading round. The returns for the long put strategy are between roughly $14 \%$ and $32 \%$. All returns are significant at a $1 \%$ level.

The results for the long-short strategy in Panel B are for all Fama-French and Carhart factor adjusted returns across maturities and moneyness groups significantly larger than zero, increase with moneyness, with the time to maturity and with the range between $0.14 \%$ and $2.22 \%$ per trading round.

Also for the delta-hedged strategy in Panel $\mathrm{C}$ we obtain results that are in line with our hypotheses. Once we control for $\Delta$-risk, the significance of the returns for the call option portfolio evaporates completely and in many cases for the put portfolio. The negative correlation

${ }^{41}$ We obtain the returns by first computing the average return for each trading round (i.e., maximum one month of holding period) and then averaging over all month. 
between volatility and returns might be an explanation for why some of the put portfolio returns remain significant.

In Appendix 4 we also report results of a second set of trading strategies, where we choose as trading signals decreases in the $O M S^{+}$and $O M S^{-}$measures. The results are qualitatively the same as for the trading strategy that trades on the levels of the $O M S$ measures.

One possible interpretation of the predictability and the significant trading profits for the long options and long-short stock strategy could be that options market sidedness picksup mostly momentum signals. Therefore, in Appendix 4 we also test whether the $O M S$ measure reflects more information than pure momentum. ${ }^{42}$ We find that option market sidedness captures directional information in option trading that is clearly different from pure momentum signals and that also helps to identify (private) directional signals for securities that a simple momentum strategy would neglect.

\section{Option Demand and Future Stock Market Trading}

A possible alternative explanation of our results is that options market sidedness is related to illiquidity of the stock. Informed option market trading could have an impact on stock market trading or reflect that traders expect the stock to be relatively illiquid and hence they prefer to use options to exploit their information. The predictive power of $O M S$ would in such cases result from illiquidity premia. Hence, if more options market one-sidedness (i.e., lower $O M S$ values) indicates higher asymmetric information in the options market rather than illiquidity premia, we would expect that option demand imbalances are not able to explain the future and contemporaneous variation in stock market illiquidity. To test this, we regress the stock illiquidity measure as suggested by Amihud (2002) (ILLQ $Q_{\text {Amihud }}$ ) on our options market sidedness measures.

Second, we show in this section that two-sided (as measured by $O M S$ ) markets are associated with higher stock market trading volume. This is important since it supports that the

\footnotetext{
${ }^{42}$ See Appendix 4 for details.
} 
strong return predictive power of $O M S$ is not due to an increase in hedging demand. To this end, we regress stock market trading volume on our $O M S$ measures.

In Table 7, we report the results from FMB-regressions that explore the relationship of stock market trading and options market sidedness.43

\section{INSERT TABLE 7 ABOUT HERE}

In columns (I) and (II), ILLQ $Q_{\text {Amihud }}$ is the dependent variable. In column (I) we use the lagged $O M S$ measure as independent variable and in column (II) we use $O M S$ contemporaneously. Neither the lagged nor the contemporaneous $O M S$ measure yield a significant coefficient. This provides support for our hypothesis that the return predictability, which we find in the above, is not related to stock market liquidity premia.

In columns (III) and (IV), VOL $L_{\text {Stock }}$ is the dependent variable. In column (III) we use the lagged $O M S$ measure as independent variable and in column (IV) we use $O M S$ contemporaneously. The coefficients for all $O M S$ measures are positive and significant, reflecting a positive relation between upward level shifts in trading activities in the stock market and a jointly increasing excess demand across all option contract types (i.e., two-sided markets). Conversely, a more one-sided options market is correlated with lower trading activities in the stock market. These findings supports the insight in Easley et al. (1998) that informed trading in the options market is more likely for firms with lower trading volumes. Moreover, it also emphasizes our hypothesis that trading in the stock market (and hence options market trading that is potentially related to hedging demand) is related to level shifts in the demand across all option types and moneyness categories and not to options market one-sidedness.

Overall, the results support our hypothesis that the predictive ability of $O M S$ for stock returns is associated with asymmetric information rather than with stock market trading related risk premia, spillover effects or hedging demand.

\footnotetext{
${ }^{43}$ We have also estimated panel OLS regressions with and without firm level fixed effects as well as with standard errors clustered by firm level or by firm level and month. The quality of our results remains unchanged.
} 


\section{Option Price Pressure and Informed Option Demand}

A very natural extension of our study is to explore the response of options market makers to options market sidedness, or, put differently, the relation between informed option demand and price pressure in the options market.

Easley et al. (1998) find that the price pressure on call or put options increases with the relative amount of informed traders and the probability of the arrival of a positive or negative signal. Other studies like Back (1993), Cao and Wei (2010), Wei and Zheng (2010), Garleanu et al. (2009), Muravyev (2013) and Ni et al. (2008) also show that asymmetric information, and thus informed trading activities coincide with a widening of option bid-ask spreads. ${ }^{44}$ This implies that market makers, who cannot perfectly hedge their inventories, observe in the evening, when the open interest is reported, the demand pressure in a particular option type and increase on the next day the option bid-ask spreads for the respective contract (see e.g., Easley et al. 1998, Garleanu et al. 2009, Kyle 1982, Ni et al. 2008).

Therefore, we expect that a higher options market one-sidedness (i.e., lower values of $O M S$ ) predicts wider option bid-ask spreads for the respective options that are bought by the informed investors 45

Using again FMB-regressions, we regress the OTM call and put spreads on the lagged $O M S^{+}$and $O M S^{-}$measure respectively and we also add stock specific control variables e.g., size, past long-term stock returns and stock return volatility and options market specific controls such as option volume.

In Table 8 we report the option spread FMB-regression results. ${ }_{46}^{46}$

\section{INSERT TABLE 8 ABOUT HERE}

\footnotetext{
${ }^{44}$ See e.g. Madhavan (2000) for a comprehensive review of theoretical models that establish asymmetric information and inventory risk costs of market making.

45 Since market makers do not observe the open interest intra-daily, they can only react on the next day to the information contained in open interest changes. This implies that the profits of the informed investors are not quickly wiped out because of liquidity effects.

${ }^{46}$ We have also estimated panel OLS regressions with and without firm level fixed effects as well as with firm level or firm level and month clustered standard errors. Our results do not qualitatively change and we find no evidence for a substantial firm effect.
} 
The spread regressions in columns (I) and (III) confirm the expected negative relation between the lagged $O M S$ measures and the stock individual bid-ask spread. In addition, the results are almost identical for both call and put option spreads, which corroborates that the impact of the demand pressure is similar for the positive and negative information case. All results are robust to the controls that we include in columns (II) and (IV). Overall, the findings show that the $O M S$ measure can be useful as a new liquidity measure in the options market 47

Intuitively, the reaction of the market makers to the informed demand contributes to a relative increase in future pricing inefficiencies between both market sides, for instance to violations of the put-call parity $(\mathrm{PCP}){ }^{48}$ Therefore, we also test in this section whether more one-sided options markets, i.e., lower $O M S$ measure values, predict larger violations of the PCP.

Apart from arguably the demand pressure of informed traders, there are many other reasons in the real market that determine the empirically observed violations of the PCP. For American options, the early exercise premium, and for all option types general frictions such as short-sale constraints or taxes, can lead to violations of the PCP. However, for our purposes the general fact that the PCP might be violated is irrelevant since we are interested whether higher values of the PCP violations are associated with more one-sided options markets.

Cremers and Weinbaum (2010) point out that deviations from the PCP are not only related to inefficient pricing that could be easily arbitraged away and show that informed trading may increase deviations from the PCP. In addition, in the sequential trading model of Easley et al. (1998) informed trading can result in violations of the put-call parity. Thus, we expect that options market one-sidedness also predicts absolute PCP deviations with a positive sign.

Kamara and Miller (1995) and Ackert and Tian (2001) show that PCP deviations reflect

\footnotetext{
${ }^{47}$ In unreported results we find that options market sidedness does not affect option liquidity risk premia. This is in line with the notion of informed option trading as exploitation of private directional information, which by itself, however, remains unobserved by the uninformed investors.

${ }^{48}$ Previous studies such as Cremers and Weinbaum (2010) or Easley et al. (1998) provide evidence in support of this hypotheses.
} 
option liquidity risk by regressing PCP deviations on option liquidity risk proxies. In order to investigate the relation between our measure of option demand asymmetry and PCP deviations, we first compute:

$$
|P C P 1|=\left|a^{C}-b^{P}+K e^{-r T}-S^{b i d}\right|,
$$

and

$$
|P C P 2|=\left|a^{P}-b^{C}+S^{a s k}-K e^{-r T}\right|,
$$

where $a$ and $b$ denote the daily ask and bid price for the put and call options, respectively. $T$ is the time to maturity in days, $K$ is the strike price and $r$ is the risk free rate. The FMBregressions also control for several other stock individual and options market specific factors such as size, book-to-market, past returns, historical volatility or trading volume. Similarly to the spread regressions, we expect a negative coefficient for the lagged $O M S$ measures, implying larger future absolute PCP violations when options markets are more one-sided.

The regression results in Table 9 yield as expected a negative predictive relation between the OMS measures and the PCP deviations. Whenever the option demand indicates asymmetric information, the future PCP deviations increase.

\section{INSERT TABLE 9 ABOUT HERE}

This supports our hypothesis that informed trading in options markets creates a one-sided demand pressure, which impacts the deviations of the pricing relations in the options market. The findings imply that informed options market demand contributes to deviations from no-arbitrage pricing relations, which puts a fundamental principle of most option pricing approaches further into question 49

\footnotetext{
${ }^{49}$ Also all of our results in this section qualitatively hold if we use only the $75 \%$ largest firms in our sample in terms of trading volume. Hence, it is unlikely that our results are mainly driven by the fact that illiquid options, that is those options that are most likely to exhibit PCP deviations, drive the results.
} 


\section{Conclusion}

This paper combines the concept of market sidedness with excess option demand (changes in open interest) to solve the empirical challenge of separating directional from uninformed trading motives and from other sources of return predictability than directionally informed demand in widely available, unsigned options data.

The guiding idea of our "options market sidedness" (OMS) measure is that if traders obtain informative signals on the future direction of stock returns, and decide to exploit their information in the options market, they create an imbalance in the excess option demand between those contract types that they are likely to buy and other contract types whose demand is predominantly driven by hedging demand, liquidity or noise trading. The larger the informed demand, the more one-sided is the options market. Informed investors tend to buy those contract types that allow them to take a leveraged position on the direction of their information (i.e., OTM options).

Hence, the measure of $O M S$ relates the changes in open interest of OTM option contracts, that are likely to be used by directionally informed traders, with the changes in open interest for low leverage (ITM) option contracts, that are unlikely to be used by directionally informed traders and indicates trading on positive and negative signals as well as the strength of the information at an individual security level.

Using daily data of all securities at the intersection of the OptionMetrics Ivy DB, CRSP daily return files and Compustat from January 1996 until December 2009 we find: First, the $O M S$ measure for the call (put) market predicts increasing (decreasing) stock excess returns, beyond past returns and several other controls. Second, returns for option and stock investment strategies that trade on the informed demand in options are high. Third, prior to high information events such as M\&A announcements, the one-sidedness of the markets increases, consistent with the increased asymmetric information. After the announcement the option demand is again more two-sided, reflecting the decrease in information asymmetry. Fourth, other trading motives such as volatility informed trading, liquidity or hedging demand 
do not drive our results.

Our study also contributes empirical evidence to the potential sources of a demand related option price pressure as modeled by Garleanu et al. (2009). We show that at higher levels of informed option demand future options market liquidity is lower and pricing inefficiencies are larger. 


\section{References}

Ackert, Lucy F. and Yisong S. Tian, "Efficiency in Index Options Markets and Trading in Stock Baskets," Journal of Banking and Finance, 2001, 25, 1607-1634.

Amihud, Yakov, "Illiquidity and Stock Returns: Cross-Section and Time-Series Effects," Journal of Financial Markets, 2002, 5, $31-56$.

Back, Kerry, "Asymmetric Information and Options," Review of Financial Studies, 1993, 6 (3), $435-472$.

Beaver, William H., "The Information Content of Annual Earnings Announcements," Journal of Accounting Research, 1968, 6, 67-92.

Black, Fisher, "Fact and Fantasy in Use of Options," Financial Analysts Journal, 1975, 31, 36-41, $61-72$.

Bollen, Nicolas P. and Robert E. Whaley, "Does Net Buying Pressure Affect The Shape of Implied Volatility Functions?," Journal of Finance, April 2004, 59 (2), 711-753.

Cao, Charles, Zhiwu Chen, and John M. Griffin, "Informational Content of Option Volume Prior to Takeovers," Journal of Business, 2005, 78 (3), 1073 - 1109.

Cao, Melanie and Jason Wei, "Option Market Liquidity: Commonality and other Characteristics," Journal of Financial Markets, 2010, 13, 20 - 48.

Chakravarty, Sugato, Huseyin Gulen, and Stewart Mayhew, "Informed Trading in Stock and Option Markets," Journal of Finance, June 2004, 59 (3), 1235-1257.

Chesney, Marc, Remo Crameri, and Loriano Mancini, "Detecting Informed Trading Activities in the Options Markets," Swiss Finance Institute Research Paper, September 2011, 11-42.

Choy, Siu Kai and Jason Wei, "Option Trading: Information or Differences in Opinion?," Journal of Banking and Finance, 2012, 36, 2299 - 2322.

Cremers, Martijn and David Weinbaum, "Deviations from Put-Call Parity and Stock Return Predictability," Journal of Financial and Quantitative Analysis, April 2010, 45 (2), 335 - 367. 
Daniel, Kent and Sheridan Titman, "Market Reactions to Tangible and Intangible Information," Journal of Finance, August 2006, 61 (4), 1605-1643.

Driessen, Joost, Pascal J. Maenhout, and Grigory Vilkov, "The Price of Correlation Risk: Evidence from Equity Options," Journal of Finance, June 2009, 64 (3).

Easley, David and Maureen O'Hara, "Price, Trade Size, and Information in Securities Markets," Journal of Financial Economics, 1987, 19 (1), 69-90.

and P.S. Srinivas, "Option Volume and Stock Prices: Evidence on where Informed Traders Trade," Journal of Finance, April 1998, 53 (2), 431-465.

, Soeren Hvidkjaer, and Maureen O'Hara, "Is Information Risk a Determinant of Asset Returns?," Journal of Finance, 2002, 57 (5), 2185-2221.

Fama, Eugene F. and James D. MacBeth, "Risk, Return, and Equilibrium: Empirical Tests," Journal of Political Economy, 1973, 81 (3), 607 - 636.

Garleanu, Nicolae, Lasse Heje Pedersen, and Allen M. Poteshman, "Demand-Based Option Pricing," Review of Financial Studies, 2009, 22 (10), 4259-4299.

Ge, Li, Tse-Chun Lin, and Neil D. Pearson, "Why Does the Option to Stock Volume Ratio Predict Stock Returns?," Working Paper, 2015.

Grossman, Sanford J and Joseph E Stiglitz, "On the Impossibility of Informationally Efficient Markets," American Economic Review, June 1980, 70 (3), 393-408.

Johnson, Travis L. and Eric C. So, "The Option to Stock Volume Ratio and Future Returns," Journal of Financial Economics, November 2012, 106, 262-286.

Kamara, Avraham and Thomas W. Miller, "Daily and Intradaily Tests of European Put-CallParity," Journal of Financial and Quantitative Analysis, December 1995, 30 (4), 519-539.

Kyle, Albert S., "Continuous Auctions and Insider Trading," Econometrica, November 1982, 53 (6), $1315-1335$.

Lakonishok, Josef, Inmoo Lee, Neil D. Pearson, and Allen M. Poteshman, "Option Market Activity," Review of Financial Studies, 2007, 20 (3), 814-857. 
Madhavan, Ananth, "Market Microstructure: A Survey," Journal of Financial Markets, August 2000, $3(3), 205-258$.

McKeon, Ryan, "Returns from Trading Call Options," Journal of Investing, 2013, Summer, 64-77.

Muravyev, Dimitriy, "Order Flow and Expected Option Returns," Working Paper, November 2013, Boston College.

Ni, Sophie X., "Stock Option Returns: A Puzzle," Working paper, 2010, Hong Kong University of Science and Technology.

, Jun Pan, and Allen M. Poteshman, "Volatility Information Trading in The Option Market," Journal of Finance, June 2008, 63 (3), 1059-1091.

Pan, Jun and Allen M. Poteshman, "The Information in Option Volume for Future Stock Prices," Review of Financial Studies, 2006, 19 (3), 871 - 908.

Poteshman, Allen M., "Unusual Option Market Activity and The Terrorist Attacks of September 11, 2001," Journal of Business, 2006, 79 (4), 1703-1726.

Puhan, Tatjana Xenia, "Volatility Information in Index Option Demand," Working Paper, University of Zurich, February 2014.

Roll, R., E. Schwartz, and A. Subrahmanyam, "O/S: The relative trading activity in options and stock," Journal of Financial Economics, 2010, 96 (1), 1-17.

Sarkar, Asani and Robert A. Schwartz, "Market Sidedness: Insights into Motives for Trade Initiation," Journal of Finance, 2009, 64 (1), 375-423.

Schwert, G. William, "Markup Pricing in Mergers and Aquisitions," Journal of Financial Economics, 1996, 41, 153-192.

Wei, Jason and Jinguo Zheng, "The Equity Premium Puzzle and The Risk-Free Rate Puzzle," Journal of Banking and Finance, 2010, 34, 2897 - 2916.

Xing, Yuhang, Xiaoyan Zhang, and Rui Zhao, "What Does the Individual Option Volatility Smirk Tell Us About Future Equity Returns," Journal of Financial and Quantitative Analysis, June 2010, 45 (3), $641-662$. 


\section{Tables \& Figures}

Table 2: Descriptive Statistics of Sample Variables. The table provides summary descriptive statistics for sample variables across the full sample period from January 1996 until December 2009. The table reports the mean, the standard deviation (Std), the median, the 25 percent (Q25) and the 75 percent quantile (Q75) across all sample firms. $O M S^{+}$and $O M S^{-}$are the options market sidedness measures for the positive and negative information case, respectively (for details see Section 2). BETA is the individual stock market beta, $S I Z E$ is the logarithm of market equity. $B M$ is the logarithm of the book-to-market ratio measured by book equity divided by, market equity using the fiscal yearend value preceding year. The realized volatility $(R V)$ is in basis points and is defined as in $\mathrm{Ni}$ et al. (2008) as 10,000 times the difference of an underlying stock's intraday high and low prices divided by the closing stock price. $M O M$ is the cumulative return over a 60 days backward looking window. $S T D$ is the average realized standard deviation obtained from the daily returns over a 60 days backward looking window. SPREAD $D_{O T M}^{C}$ and $S P R E A D_{I T M}^{C}$ are the median daily relative bid-ask spreads of call options that are OTM or ITM. SPREAD PTM and $S P R E A D_{I T M}^{P}$ are the median daily relative bid-ask spreads of put options that are OTM or ITM. $S V O L_{O T M}^{C}$ and $S V O L_{I T M}^{C}$ denote the square root of the daily median call option trading volume that are OTM or ITM. $S V O L_{O T M}^{P}$ and $S V O L_{I T M}^{P}$ denote the square root of the daily median put option trading volume that are OTM or ITM. The descriptives for the $O M S$ measure, the daily option spreads and option volume are formed using all days where the respective variable was nonzero.

\begin{tabular}{|c|c|c|c|c|c|c|}
\hline & Mean & Std & Q25 & Median & Q75 & No. Obs. \\
\hline$O M S_{t}^{+}$ & 0.423 & 0.398 & 0.114 & 0.473 & 0.751 & $5,015,363$ \\
\hline$O M S_{t}^{-}$ & 0.461 & 0.397 & 0.158 & 0.526 & 0.795 & $5,396,556$ \\
\hline$B E T A$ & 1.206 & 0.418 & 0.842 & 1.095 & 1.442 & $7,011,930$ \\
\hline$S I Z E$ & 7.208 & 1.629 & 6.089 & 7.115 & 8.221 & $7,011,930$ \\
\hline$B M$ & 0.784 & 5.784 & 0.256 & 0.446 & 0.745 & $7,011,930$ \\
\hline$R V$ & 415.06 & 359.582 & 198.413 & 315.217 & 510.386 & $7,011,930$ \\
\hline$M O M$ & 0.032 & 0.267 & -0.091 & 0.0378 & 0.160 & $7,011,930$ \\
\hline$S T D$ & 0.0312 & 0.019 & 0.018 & 0.026 & 0.039 & $7,011,930$ \\
\hline$S P R E A D_{O T M}^{C}$ & 1.108 & 0.780 & 0.303 & 1.028 & 2.000 & $6,918,180$ \\
\hline$S P R E A D_{I T M}^{C}$ & 0.100 & 0.145 & 0.047 & 0.075 & 0.111 & $6,920,299$ \\
\hline$S P R E A D_{I T M}^{P}$ & 0.115 & 0.180 & 0.049 & 0.078 & 0.121 & $6,799,572$ \\
\hline$S P R E A D_{O T M}^{P}$ & 1.074 & 0.739 & 0.353 & 1.000 & 2.000 & $6,797,715$ \\
\hline$S V O L_{O T M}^{C}$ & 4.423 & 4.558 & 1.871 & 3.162 & 5.292 & $6,918,180$ \\
\hline$S V O L_{I T M}^{C}$ & 3.507 & 3.399 & 1.581 & 2.739 & 4.123 & $6,920,299$ \\
\hline$S V O L_{I T M}^{P}$ & 3.741 & 4.429 & 1.581 & 2.739 & 4.472 & $6,799,572$ \\
\hline$S V O L_{O T M}^{P}$ & 4.559 & 5.021 & 2.000 & 3.162 & 5.292 & $6,797,715$ \\
\hline
\end{tabular}




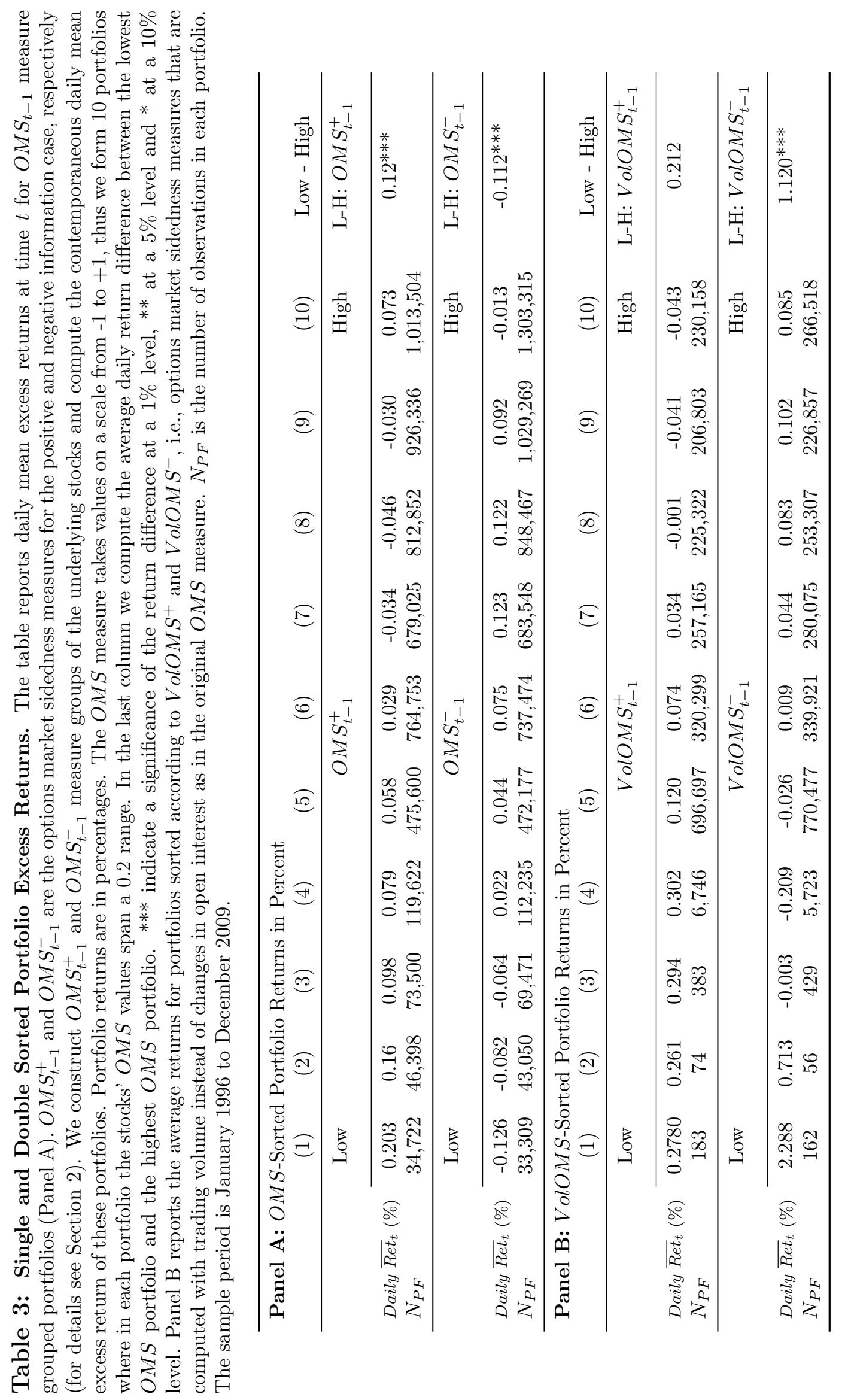


Table 4: FMB-Regression Results for Daily Individual Stock Excess Returns on the Directional $O M S$ Measures and Controls. The table provides daily FMB-regression results of individual stock's excess returns $(R E T)$ on the directional $O M S$ measures as well as on control variables. Returns are in percentages. $O M S_{t-1}^{+}$and $O M S_{t-1}^{-}$are the lagged options market sidedness measures for the positive and negative information case, respectively (for details see Section 2]. $O M S_{t-1}^{2,+}$ and $O M S_{t-1}^{2,-}$ are the corresponding quadratic terms. $S V O L_{O T M}^{C}$ and $S V O L_{I T M}^{C}$ is the square root of the daily median call option trading volume that are OTM or ITM. $S V O L_{O T M}^{P}$ and $S V O L_{I T M}^{P}$ is the square root of the daily median put option trading volume that are OTM or ITM. CP - RATIO is a daily ratio of the aggregated changes in open interest for call options divided by the aggregated changes in the open interest for put options minus one. $\overline{\Delta O I}_{O T M, t-1}^{C}$ is a 30-day rolling window mean of the change in open interest in OTM call options. $\overline{\Delta O I}_{O T M, t-1}^{P}$ is a 30-day rolling window mean of the change in open interest in OTM put options. EAD is a dummy that is one if the day is an earnings announcement day and zero otherwise. The results for the stock related control variables (Stock Controls) are omitted. Stock Controls includes: EAD, market beta (BETA), size (SIZE), book-tomarket $(B M)$, momentum $(M O M)$, volatility $(S T D)$. The definitions of the control variables are summarized in Appendix 1. Newey-West robust t-statistics are in parentheses (20 lags). *** indicate a significance at a $1 \%$ level, ${ }^{* *}$ at a $5 \%$ level and ${ }^{*}$ at a $10 \%$ level. The $R^{2}$ is the average cross-sectional adjusted $R^{2}$. No. Firms is the overall number of stocks in the regression. The sample period is January 1996 to December 2009.

\begin{tabular}{|c|c|c|c|c|c|c|c|c|}
\hline$R E T_{t}$ & (I) & (II) & (III) & (IV) & $(\mathrm{V})$ & (VI) & (VII) & (VIII) \\
\hline Constant & $\begin{array}{l}0.045 \\
(1.59)\end{array}$ & $\begin{array}{l}0.048^{*} \\
(1.67)\end{array}$ & $\begin{array}{l}-0.087 \\
(-1.47)\end{array}$ & $\begin{array}{c}-0.122^{* *} \\
(-1.97)\end{array}$ & $\begin{array}{c}-0.095^{*} \\
(-1.66)\end{array}$ & $\begin{array}{l}-0.086 \\
(-1.46)\end{array}$ & $\begin{array}{l}-0.051 \\
(-0.85)\end{array}$ & $\begin{array}{l}-0.05 \\
(-0.84)\end{array}$ \\
\hline$O M S_{t-1}^{+}$ & $\begin{array}{l}-0.166^{* * *} \\
(-11.55)\end{array}$ & $\begin{array}{c}-0.502^{* * *} \\
(-8.08)\end{array}$ & $\begin{array}{c}-0.169 * * * \\
(-11.57)\end{array}$ & $\begin{array}{c}-0.162^{* * *} \\
(-10.13)\end{array}$ & $\begin{array}{c}-0.169^{* * *} \\
(-11.68)\end{array}$ & $\begin{array}{c}-0.169^{* * *} \\
(-11.66)\end{array}$ & $\begin{array}{c}-0.158^{* * *} \\
(-12.11)\end{array}$ & $\begin{array}{c}-0.169^{* * *} \\
(-11.49)\end{array}$ \\
\hline$O M S_{t-1}^{-}$ & $\begin{array}{l}0.167^{* * *} \\
(10.72)\end{array}$ & $\begin{array}{c}0.593^{* * *} \\
(9.62)\end{array}$ & $\begin{array}{c}0.116^{* * *} \\
(7.18)\end{array}$ & $\begin{array}{c}0.121^{* * *} \\
(7.46)\end{array}$ & $\begin{array}{c}0.115^{* * *} \\
(7.1)\end{array}$ & $\begin{array}{c}0.116^{* * *} \\
(7.15)\end{array}$ & $\begin{array}{c}0.136^{* * * *} \\
(9.09)\end{array}$ & $\begin{array}{c}0.136^{* * *} \\
(7.45)\end{array}$ \\
\hline$O M S_{t-1}^{2,+}$ & $\begin{array}{l}0.215^{* * *} \\
(13.34)\end{array}$ & $\begin{array}{c}0.21^{* * *} \\
(13.12)\end{array}$ & $\begin{array}{c}0.195^{* * *} \\
(13.54)\end{array}$ & $\begin{array}{c}0.184^{* * *} \\
(11.93)\end{array}$ & $\begin{array}{c}0.194^{* * *} \\
(13.58)\end{array}$ & $\begin{array}{c}0.194^{* * *} \\
(13.5)\end{array}$ & $\begin{array}{c}0.174^{* * *} \\
(12.55)\end{array}$ & $\begin{array}{c}0.195^{* * *} \\
(13.43)\end{array}$ \\
\hline$O M S_{t-1}^{2,-}$ & $\begin{array}{l}-0.255^{* * *} \\
(-16.22)\end{array}$ & $\begin{array}{c}-0.254^{* * *} \\
(-16.16)\end{array}$ & $\begin{array}{c}-0.227^{* * *} \\
(-14.12)\end{array}$ & $\begin{array}{c}-0.239 * * * \\
(-14.45)\end{array}$ & $\begin{array}{c}-0.224^{* * *} \\
(-13.92)\end{array}$ & $\begin{array}{c}-0.226^{* * *} \\
(-14.02)\end{array}$ & $\begin{array}{c}-0.223^{* * *} \\
(-14.42)\end{array}$ & $\begin{array}{c}-0.225^{* * *} \\
(-14.15)\end{array}$ \\
\hline$O M S_{t}^{+}$ & & $\begin{array}{c}0.344^{* * *} \\
(6.06)\end{array}$ & & & & & & \\
\hline$O M S_{t}^{-}$ & & $\begin{array}{c}-0.435^{* * * *} \\
(-7.6)\end{array}$ & & & & & & \\
\hline$S V O L_{O T M}^{C}$ & & & $\begin{array}{c}0.078^{* * *} \\
(21.39)\end{array}$ & $\begin{array}{c}0.075^{* * *} \\
(21.11)\end{array}$ & $\begin{array}{c}0.080^{* * *} \\
(21.51)\end{array}$ & $\begin{array}{c}0.079^{* * *} \\
(21.7)\end{array}$ & $\begin{array}{c}0.067^{* * *} \\
(19.62)\end{array}$ & $\begin{array}{c}0.077^{* * * *} \\
(21.3)\end{array}$ \\
\hline$S V O L_{I T M}^{C}$ & & & $\begin{array}{c}-0.027^{* * *} \\
(-4.99)\end{array}$ & $\begin{array}{c}-0.027^{* * *} \\
(-4.97)\end{array}$ & $\begin{array}{c}-0.028^{* * *} \\
(-5.03)\end{array}$ & $\begin{array}{c}-0.027^{* * *} \\
(-4.91)\end{array}$ & $\begin{array}{c}-0.017^{* * * *} \\
(-3.29)\end{array}$ & $\begin{array}{c}-0.077^{* * * *} \\
(-4.84)\end{array}$ \\
\hline$S V O L_{I T M}^{P}$ & & & $\begin{array}{c}0.082^{* * *} \\
(13.60)\end{array}$ & $\begin{array}{c}0.08^{* * *} \\
(13.29)\end{array}$ & $\begin{array}{c}0.084^{* * *} \\
(13.45)\end{array}$ & $\begin{array}{c}0.083^{* * *} \\
(13.51)\end{array}$ & $\begin{array}{c}0.062^{* * * *} \\
(9.82)\end{array}$ & $\begin{array}{c}0.081^{* * *} \\
(13.80)\end{array}$ \\
\hline$S V O L_{O T M}^{P}$ & & & $\begin{array}{c}-0.15^{* * *} \\
(-28.00)\end{array}$ & $\begin{array}{c}-0.147^{* * *} \\
(-27.21)\end{array}$ & $\begin{array}{c}-0.152^{* * *} \\
(-28.56)\end{array}$ & $\begin{array}{c}-0.152^{* * *} \\
(-28.45)\end{array}$ & $\begin{array}{c}-0.138^{* * *} \\
(-26.20)\end{array}$ & $\begin{array}{c}-0.135^{* * * *} \\
(-28.09)\end{array}$ \\
\hline$C P-R A T I O$ & & & & $\begin{array}{c}0.001 * * * \\
(3.94)\end{array}$ & & & & \\
\hline$\overline{\Delta O I}_{O T M, t-1}^{C}$ & & & & & $\begin{array}{c}0.000^{*} \\
(1.68)\end{array}$ & & & \\
\hline$\overline{\Delta O I}_{O T M, t-1}^{P}$ & & & & & $\begin{array}{c}-0.001^{* * *} \\
(-6.70)\end{array}$ & & & \\
\hline$\left(\overline{\Delta O I}_{O T M, t-1}^{C}\right.$ & & & & & & & & \\
\hline$\left.-\overline{\Delta O I}_{O T M, t-1}^{P}\right)$ & & & & & & $\begin{array}{c}-0.001^{* * *} \\
(-5.61)\end{array}$ & & \\
\hline$O M S_{t-1}^{\sigma}$ & & & & & & & $\begin{array}{l}0.007 \\
(1.47)\end{array}$ & \\
\hline$O M S_{t-1}^{C} \cdot E A D_{t}$ & & & & & & & & $\begin{array}{c}3.56 \\
(1.00)\end{array}$ \\
\hline$O M S_{t-1}^{P} \cdot E A D_{t}$ & & & & & & & & $\begin{array}{l}-1.496 \\
(-1.07) \\
\end{array}$ \\
\hline Stock Controls & No & No & Yes & Yes & Yes & Yes & Yes & Yes \\
\hline$A d j . R^{2}$ & 0.003 & 0.006 & 0.112 & 0.119 & 0.113 & 0.113 & 0.128 & 0.132 \\
\hline No. Firms & 4,155 & 4,155 & 4,155 & 4,155 & 4,155 & 4,155 & 4,155 & 4,155 \\
\hline
\end{tabular}




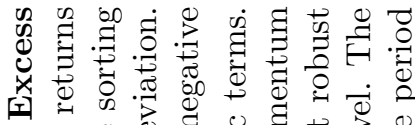
w 융 뭉

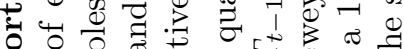

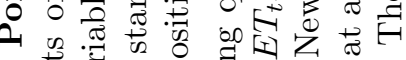

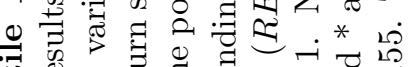

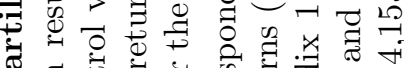

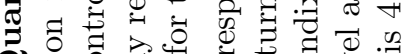
ठ. $\checkmark$ 声可

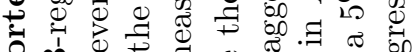

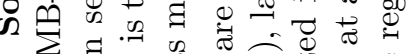

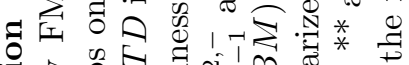

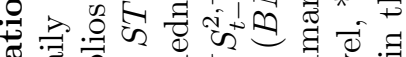

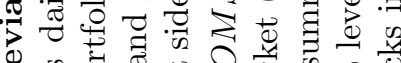
of 0 i 0 क . T)

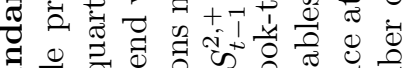

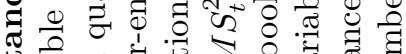

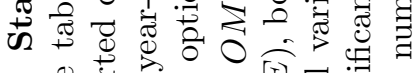

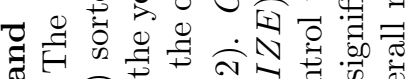
西 为 政

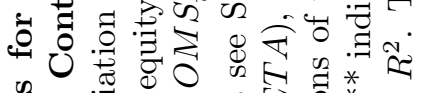

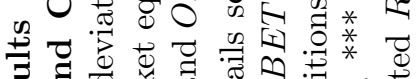

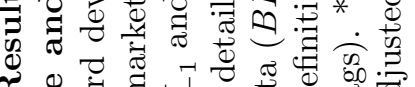

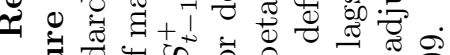
5

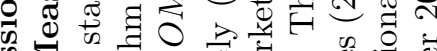

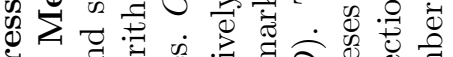

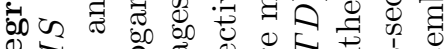

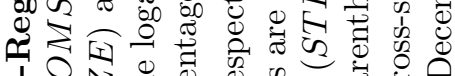

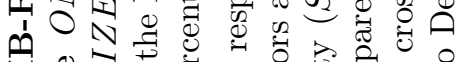

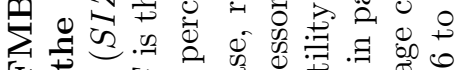

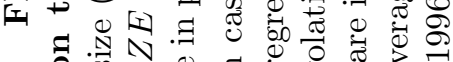

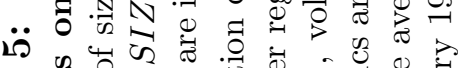
0

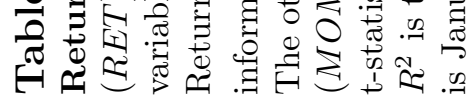

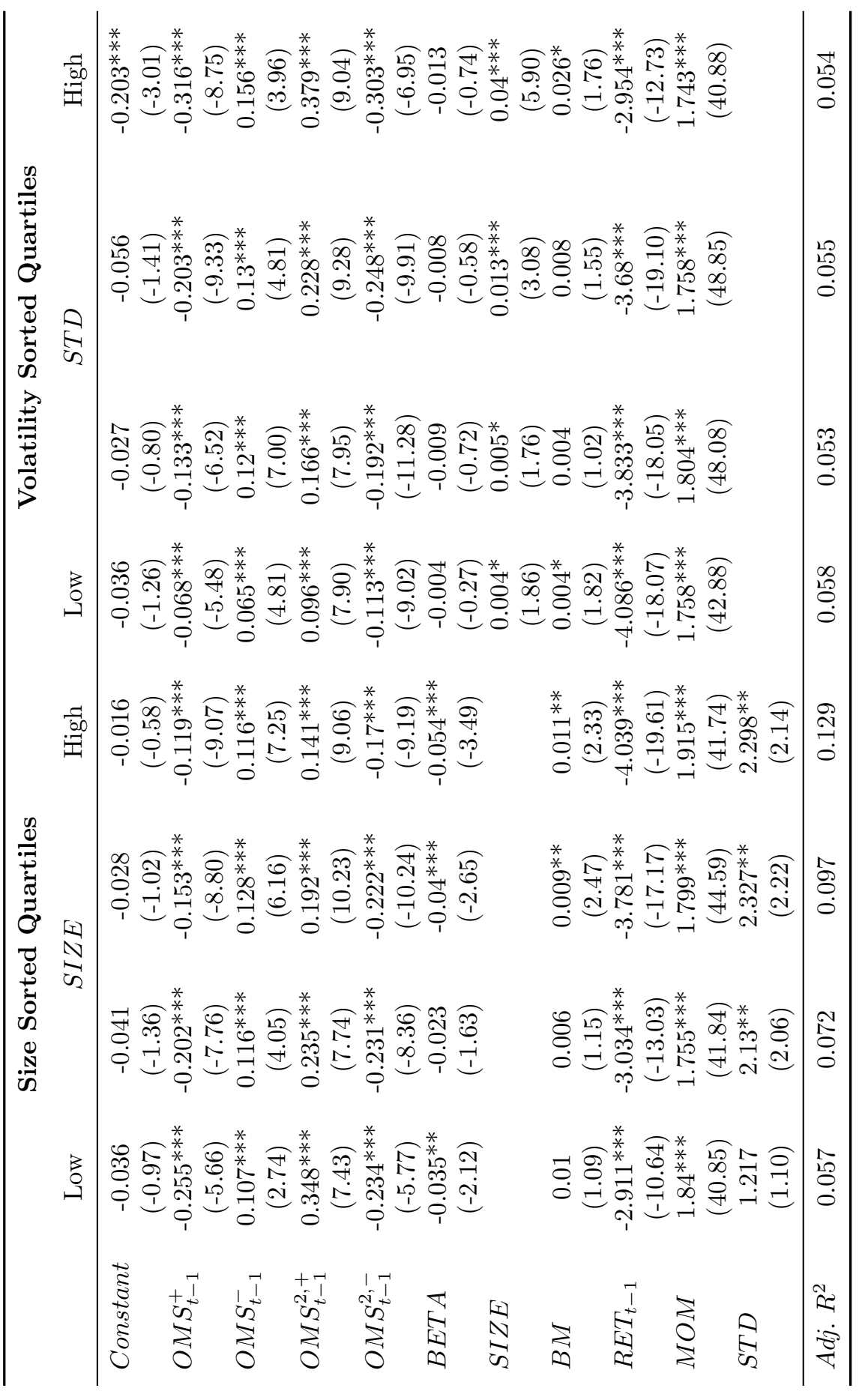




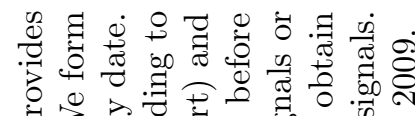

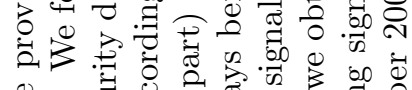

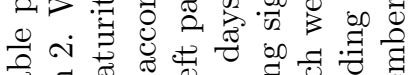

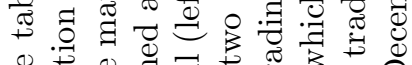

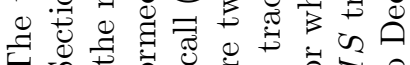

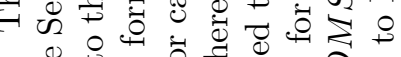

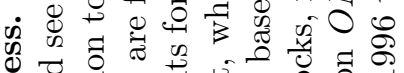

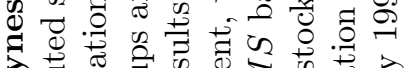

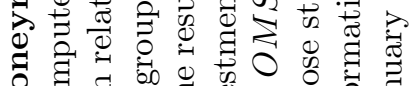

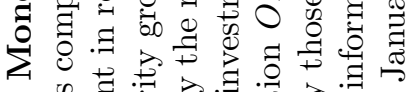
음

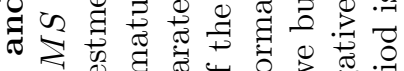
ข

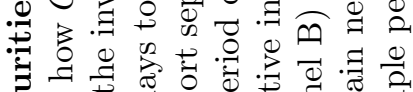

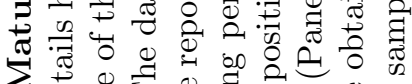

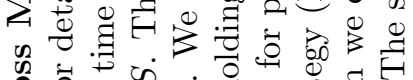
0.

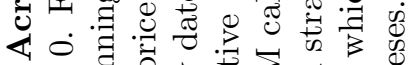

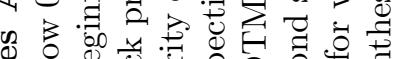
.00 : 0.

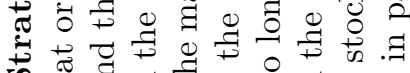
क

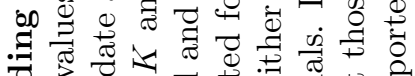
की सं $\approx 0$ 要

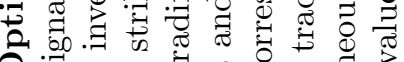

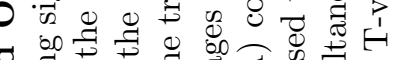
उ.

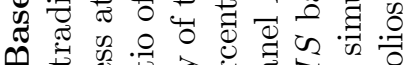

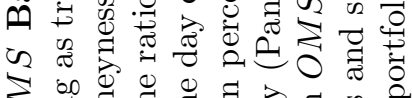
ऽ. 记

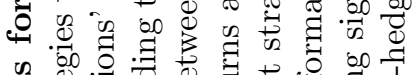
马.

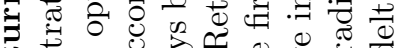
ए

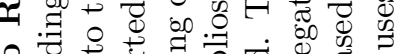

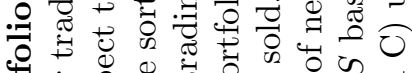
㻤苛 ค ज

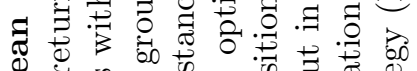

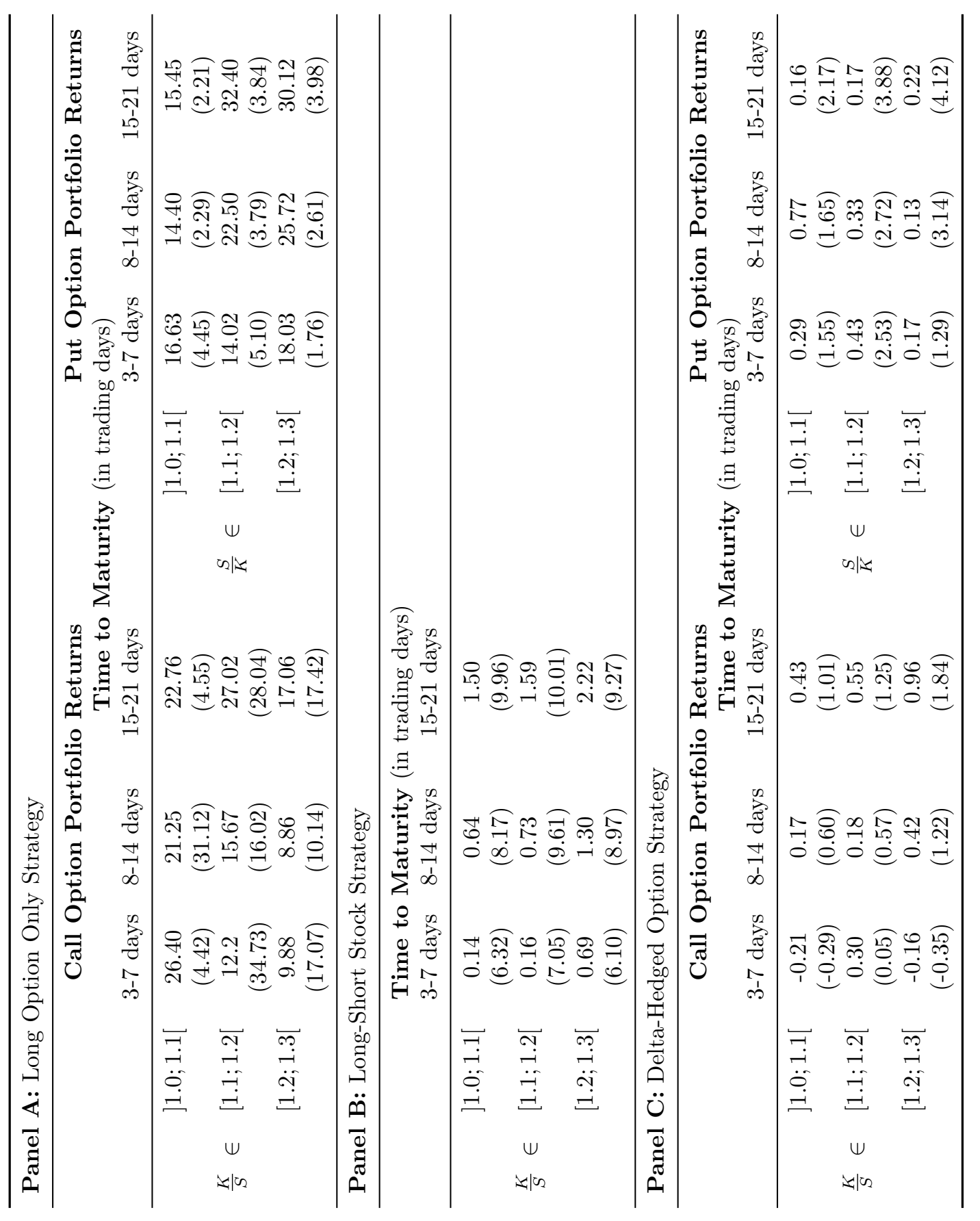

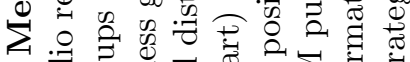

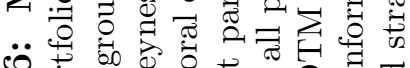
(6)

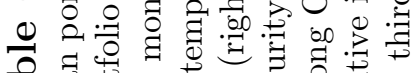

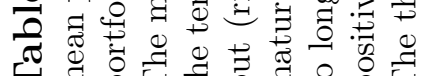

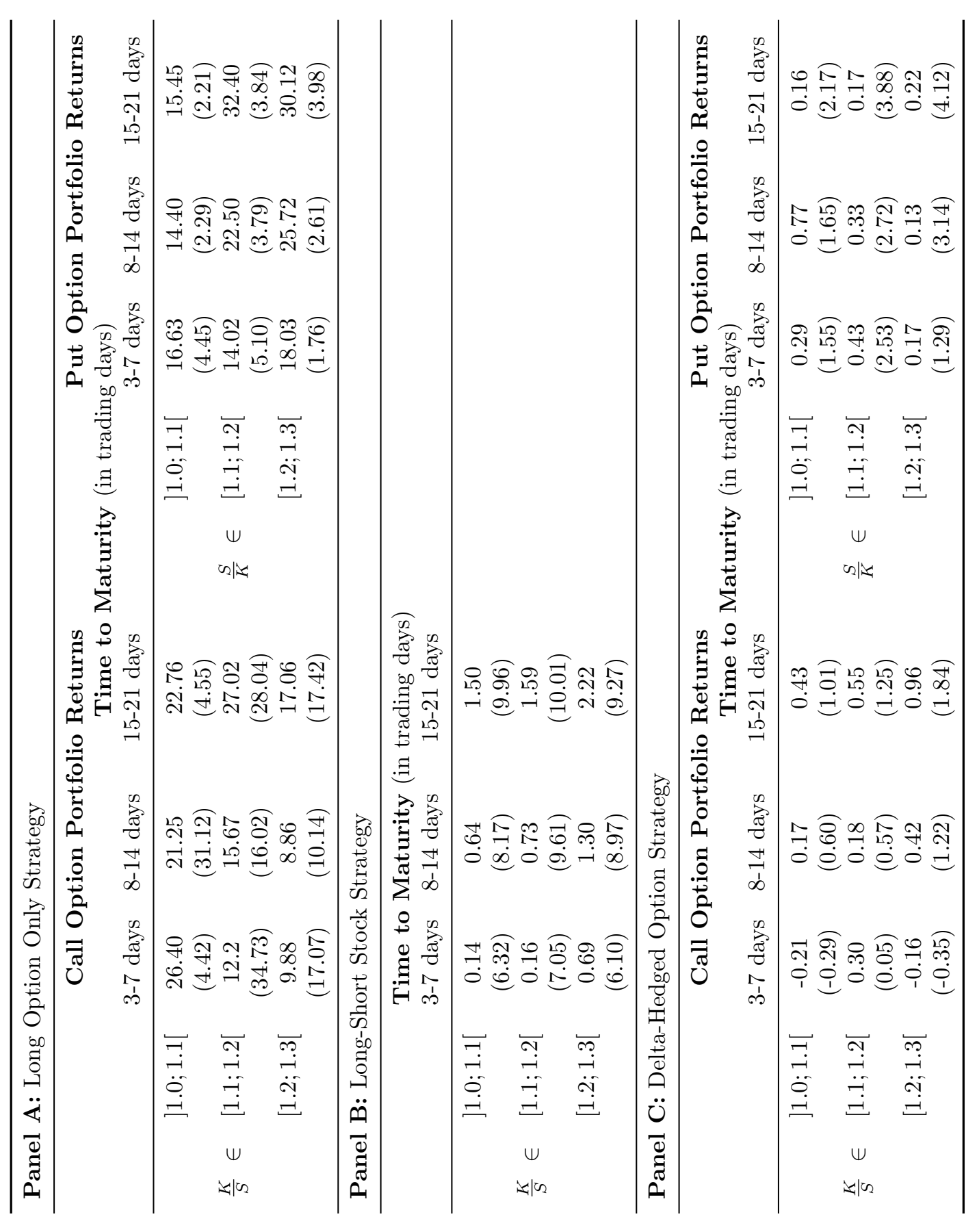


Table 7: FMB-Regression Results for Stock Liquidity Related Measures on the $O M S$ measure and Controls. The table provides daily FMB-regression results. In columns (I) and (II) the dependent variable is the stock individual Amihud (2002) liquidity measure (ILLIQ $\left.Q_{\text {Amihud }}\right)$, in columns (III) and (IV) we use the stock trading volume $\left(V O L_{\text {Stock }}\right)$ as the regressand. ILLIQ $Q_{\text {Amihud }}$ is computed as $\left(1 \times 10^{10} *\right.$ $|R E T|) / V$ olume, where Volume is the daily trading volume of a stock. $V O L_{S t o c k}$ is the logarithm of the daily trading volume of a stock. $O M S_{t-1}^{+}$and $O M S_{t-1}^{-}$are the lagged options market sidedness measures for the positive and negative information case, respectively (for details see Section 2). $O M S_{t-1}^{2,+}$ and $O M S_{t-1}^{2,-}$ are the corresponding quadratic terms. The other regressors are market beta $(B E T A)$, size $(S I Z E)$, bookto-market $(B M)$, lagged returns $\left(R E T_{t-1}\right)$, momentum $(M O M)$, volatility $(S T D)$. The definitions of the control variables are summarized in Appendix 1. Newey-West robust t-statistics are in parentheses (20 lags). *** indicate a significance at a $1 \%$ level, ${ }^{* *}$ at a $5 \%$ level and ${ }^{*}$ at a $10 \%$ level. The $R^{2}$ is the average cross-sectional adjusted $R^{2}$. No. Firms is the overall number of stocks in the regression. The sample period is January 1996 to December 2009.

\begin{tabular}{|c|c|c|c|c|}
\hline \multirow[t]{2}{*}{ Dependent Variable } & \multicolumn{2}{|c|}{$I L L I Q_{A m i h u d, t}$} & \multicolumn{2}{|c|}{$V O L_{S t o c k, t}$} \\
\hline & (I) & (II) & (III) & (IV) \\
\hline Constant & $\begin{array}{c}0.259^{* * *} \\
(19.32)\end{array}$ & $\begin{array}{c}0.259^{* * *} \\
(19.48)\end{array}$ & $\begin{array}{c}1.320^{* * *} \\
(46.32)\end{array}$ & $\begin{array}{c}1.328^{* * *} \\
(46.49)\end{array}$ \\
\hline$O M S_{t-1}^{C}$ & $\begin{array}{l}0.001 \\
(0.58)\end{array}$ & & $\begin{array}{c}0.034^{* * *} \\
(15.52)\end{array}$ & \\
\hline$O M S_{t-1}^{P}$ & $\begin{array}{c}0.000 \\
(-0.36)\end{array}$ & & $\begin{array}{c}0.039^{* * *} \\
(23.38)\end{array}$ & \\
\hline$O M S_{t}^{C}$ & & $\begin{array}{l}0.001 \\
(0.69)\end{array}$ & & $\begin{array}{c}0.031^{* * *} \\
(15.69)\end{array}$ \\
\hline$O M S_{t}^{P}$ & & $\begin{array}{l}-0.001 \\
(-0.81)\end{array}$ & & $\begin{array}{c}0.035^{* * *} \\
(22.86)\end{array}$ \\
\hline$I L L I Q_{A m i h u d, t-1}$ & $\begin{array}{c}0.483^{* * *} \\
(66.57)\end{array}$ & $\begin{array}{c}0.482^{* * *} \\
(66.50)\end{array}$ & & \\
\hline$V O L_{S t o c k, t-1}$ & & & $\begin{array}{c}0.781^{* * *} \\
(157.8)\end{array}$ & $\begin{array}{c}0.781^{* * *} \\
(158.19)\end{array}$ \\
\hline$B E T A$ & $\begin{array}{c}-0.048^{* * *} \\
(-8.16)\end{array}$ & $\begin{array}{c}-0.048^{* * *} \\
(-8.11)\end{array}$ & $\begin{array}{c}0.393^{* * *} \\
(19.69)\end{array}$ & $\begin{array}{c}0.392^{\text {*** }} \\
(19.61)\end{array}$ \\
\hline$S I Z E$ & $\begin{array}{c}-0.026^{* * *} \\
(-20.20)\end{array}$ & $\begin{array}{c}-0.026^{* * *} \\
(-20.32)\end{array}$ & $\begin{array}{c}0.162^{* * *} \\
(49.18)\end{array}$ & $\begin{array}{c}0.162^{* * *} \\
(49.19)\end{array}$ \\
\hline$R E T$ & $\begin{array}{l}-0.078 \\
(-0.91)\end{array}$ & $\begin{array}{l}-0.078 \\
(-0.92)\end{array}$ & $\begin{array}{c}0.931^{* * *} \\
(7.97)\end{array}$ & $\begin{array}{c}0.93^{* * *} \\
(7.85)\end{array}$ \\
\hline$R E T_{t-1}$ & $\begin{array}{c}-0.032^{* *} \\
(-2.07)\end{array}$ & $\begin{array}{c}-0.034^{* *} \\
(-2.07)\end{array}$ & $\begin{array}{c}-0.599 * * * \\
(-21.84)\end{array}$ & $\begin{array}{l}-0.6^{* * *} \\
(-21.82)\end{array}$ \\
\hline$M O M$ & $\begin{array}{c}0.009^{* * *} \\
(2.73)\end{array}$ & $\begin{array}{c}0.01^{* * *} \\
(2.94)\end{array}$ & $\begin{array}{c}-0.124^{* * *} \\
(-28.03)\end{array}$ & $\begin{array}{c}-0.124^{* * *} \\
(-27.97)\end{array}$ \\
\hline$S T D$ & $\begin{array}{c}-0.616^{* * *} \\
(-14.09)\end{array}$ & $\begin{array}{c}-0.621^{* * *} \\
(-14.09)\end{array}$ & $\begin{array}{c}7.903^{* * *} \\
(30.86)\end{array}$ & $\begin{array}{c}7.93^{* * *} \\
(30.90)\end{array}$ \\
\hline$A d j . R^{2}$ & 0.3 & 0.3 & 0.848 & 0.847 \\
\hline No. Firms & 4,155 & 4,155 & 4,155 & 4,155 \\
\hline
\end{tabular}


Table 8: FMB-Regression Results for Individual Firm Option Bid-Ask Spreads on the $O M S$ Measure and Controls. The table provides daily FMB-regression results using as dependent variables daily median individual firm bid-ask spreads for OTM call (model (I) and (II)) and put (model (III) and (IV)) options, respectively. $O M S^{+}$and $O M S^{-}$are the options market sidedness measures for the positive and negative information case, respectively (for details see Section 2). For the ITM and OTM option classification see Section 3 . The other regressors are size $(S I Z E)$, book-to-market $(B M)$, returns $(R E T)$, momentum $(M O M)$, volatility $(S T D)$. The definitions of the control variables are summarized in Appendix 1. $S V O L_{O T M}^{C}$ and $S V O L_{I T M}^{C}$ denote the square root of the daily median call option trading volume that are OTM or ITM. $S V O L_{O T M}^{P}$ and $S V O L_{I T M}^{P}$ denote the square root of the daily median put option trading volume that are OTM or ITM. Newey-West robust t-statistics are in parentheses (20 lags). *** indicate a significance at a $1 \%$ level, ${ }^{* *}$ at a $5 \%$ level and ${ }^{*}$ at a $10 \%$ level. The $R^{2}$ is the average crosssectional adjusted $R^{2}$. No. Firms is the overall number of stocks in the regression. The sample period is January 1996 to December 2009.

\begin{tabular}{|c|c|c|c|c|}
\hline \multirow[b]{2}{*}{ Option Spreads } & \multicolumn{2}{|c|}{ OTM Call Spread } & \multicolumn{2}{|c|}{ OTM Put Spread } \\
\hline & & (II) & & (IV) \\
\hline Constant & $\begin{array}{l}0.002 \\
(0.12)\end{array}$ & $\begin{array}{c}-0.045^{* *} \\
(-2.08)\end{array}$ & $\begin{array}{l}0.016 \\
(0.81)\end{array}$ & $\begin{array}{c}-0.09^{* * *} \\
(-4.46)\end{array}$ \\
\hline$O M S_{t-1}^{+}$ & $\begin{array}{c}-0.018^{* * *} \\
(-4.38)\end{array}$ & $\begin{array}{c}-0.011 * * * \\
(-2.91)\end{array}$ & & \\
\hline$O M S_{t-1}^{-}$ & & & $\begin{array}{c}-0.045^{* * *} \\
(-9.24)\end{array}$ & $\begin{array}{c}-0.039^{* * *} \\
(-8.91)\end{array}$ \\
\hline$S I Z E$ & & $\begin{array}{c}0.009^{* * *} \\
(4.75)\end{array}$ & & $\begin{array}{c}0.009^{* * *} \\
(4.05)\end{array}$ \\
\hline$R E T_{t-1}$ & & $\begin{array}{c}-2.261^{* * *} \\
(-35.45)\end{array}$ & & $\begin{array}{c}2.466^{* * *} \\
(38.64)\end{array}$ \\
\hline$M O M$ & & $\begin{array}{c}-0.562^{* * *} \\
(-27.50)\end{array}$ & & $\begin{array}{c}0.533^{* * *} \\
(26.63)\end{array}$ \\
\hline$S T D$ & & $\begin{array}{c}0.896^{* * *} \\
(3.12)\end{array}$ & & $\begin{array}{c}0.795^{* * *} \\
(2.82)\end{array}$ \\
\hline$S V O L_{O T M}^{C}$ & & $\begin{array}{c}-0.042^{* * *} \\
(-28.31)\end{array}$ & & \\
\hline$S V O L_{I T M}^{C}$ & & $\begin{array}{c}0.009^{* * *} \\
(7.13)\end{array}$ & & \\
\hline$S V O L_{I T M}^{P}$ & & & & $\begin{array}{c}-0.002^{* * *} \\
(-2.83)\end{array}$ \\
\hline$S V O L_{O T M}^{P}$ & & & & $\begin{array}{c}-0.038^{* * *} \\
(-28.55)\end{array}$ \\
\hline $\operatorname{Adj} . R^{2}$ & 0.001 & 0.08 & 0.002 & 0.068 \\
\hline No. Firms & 4,155 & 4,155 & 4,155 & 4,155 \\
\hline
\end{tabular}


Table 9: FMB-Regression Results for Individual Firm Put-Call Parity Violations on the $O M S$ Measure and Controls. The table provides daily FMB-regression results for daily median individual firm Put-Call Parity violations. Put-Call Parity violations are defined as described in Section 7. $O M S_{t-1}^{+}$and $O M S_{t-1}^{-}$are the options market sidedness measures for the positive and negative information case, respectively (for details see Section 2). $O M S_{t-1}^{2,+}$ and $O M S_{t-1}^{2,-}$ are the corresponding quadratic terms. $C_{t}$ is the vector of control variables that are specified below. The other regressors are market beta $(B E T A)$, size $(S I Z E)$, book-to-market $(B M)$, lagged returns $\left(R E T_{t-1}\right)$, momentum $(M O M)$, volatility $(S T D)$. The definitions of the control variables are summarized in Appendix 1. $S V O L_{O T M}^{C}$ denotes the square root of the daily median OTM call option trading volume. $S V O L_{O T M}^{P}$ denotes the square root of the daily median OTM put option trading volume. Newey-West robust t-statistics are in parentheses (20 lags). *** indicate a significance at a $1 \%$ level, ${ }^{* *}$ at a $5 \%$ level and * at a $10 \%$ level. The $R^{2}$ is the average cross-sectional adjusted $R^{2}$. No. Firms is the overall number of stocks in the regression. The sample period is January 1996 to December 2009.

\begin{tabular}{|c|c|c|c|c|c|c|}
\hline Put-Call Parity & PCP 1 & PCP 2 & PCP 1 & PCP 2 & PCP 1 & PCP 2 \\
\hline Constant & $\begin{array}{c}0.393^{* * *} \\
(40.87)\end{array}$ & $\begin{array}{c}0.391^{* * *} \\
(53.00)\end{array}$ & $\begin{array}{l}-0.076 \\
(-1.32)\end{array}$ & $\begin{array}{c}0.343^{* * *} \\
(13.61)\end{array}$ & $\begin{array}{l}-0.077 \\
(-1.35)\end{array}$ & $\begin{array}{c}0.342^{* * *} \\
(13.72)\end{array}$ \\
\hline$O M S_{t-1}^{+}$ & $\begin{array}{l}0.008 \\
(0.73)\end{array}$ & $\begin{array}{c}-0.021^{* * *} \\
(-6.54)\end{array}$ & $\begin{array}{l}0.002 \\
(0.15)\end{array}$ & $\begin{array}{c}-0.023^{* * *} \\
(-7.62)\end{array}$ & $\begin{array}{c}-0.117^{* * *} \\
(-3.64)\end{array}$ & $\begin{array}{l}-0.014^{*} \\
(-1.94)\end{array}$ \\
\hline$O M S_{t-1}^{-}$ & $\begin{array}{l}0.012 \\
(1.14)\end{array}$ & $\begin{array}{c}-0.017^{* * *} \\
(-3.48)\end{array}$ & $\begin{array}{c}-0.014^{*} \\
(-1.69)\end{array}$ & $\begin{array}{c}-0.024^{* * *} \\
(-6.00)\end{array}$ & $\begin{array}{c}-0.03^{* *} \\
(-2.17)\end{array}$ & $\begin{array}{c}-0.03 * * * \\
(-3.29)\end{array}$ \\
\hline$O M S_{t-1}^{2,+}$ & & & & & $\begin{array}{c}0.154^{* * *} \\
(4.29)\end{array}$ & $\begin{array}{l}-0.013 \\
(-1.52)\end{array}$ \\
\hline$O M S_{t-1}^{2,-}$ & & & & & $\begin{array}{c}0.02 \\
(1.01)\end{array}$ & $\begin{array}{l}0.009 \\
(0.94)\end{array}$ \\
\hline$B E T A$ & & & $\begin{array}{c}0.04^{* * *} \\
(4.31)\end{array}$ & $\begin{array}{c}-0.009^{* *} \\
(-2.40)\end{array}$ & $\begin{array}{c}0.041^{* * *} \\
(4.32)\end{array}$ & $\begin{array}{c}-0.009^{* *} \\
(-2.44)\end{array}$ \\
\hline$S I Z E$ & & & $\begin{array}{c}0.054^{* * *} \\
(8.43)\end{array}$ & $\begin{array}{c}0.012^{* * *} \\
(3.55)\end{array}$ & $\begin{array}{c}0.055^{* * *} \\
(8.53)\end{array}$ & $\begin{array}{c}0.012^{* * *} \\
(3.60)\end{array}$ \\
\hline$B M$ & & & $\begin{array}{c}0.048^{* * *} \\
(6.43)\end{array}$ & $\begin{array}{c}0.006^{* *} \\
(2.2)\end{array}$ & $\begin{array}{c}0.048^{* * *} \\
(6.44)\end{array}$ & $\begin{array}{c}0.006^{* *} \\
(2.25)\end{array}$ \\
\hline$R E T_{t-1}$ & & & $\begin{array}{l}-0.005 \\
(-0.22)\end{array}$ & $\begin{array}{c}0.046^{* * *} \\
(4.20)\end{array}$ & $\begin{array}{l}-0.011 \\
(-0.52)\end{array}$ & $\begin{array}{c}0.047^{* * *} \\
(4.31)\end{array}$ \\
\hline$M O M$ & & & $\begin{array}{c}0.062^{* * *} \\
(4.97)\end{array}$ & $\begin{array}{c}0.112^{* * *} \\
(18.46)\end{array}$ & $\begin{array}{c}0.063^{* * *} \\
(4.97)\end{array}$ & $\begin{array}{c}0.111^{* * *} \\
(18.33)\end{array}$ \\
\hline$S T D$ & & & $\begin{array}{l}-0.325 \\
(-1.29)\end{array}$ & $\begin{array}{r}-1.4^{* * *} \\
(-7.96)\end{array}$ & $\begin{array}{l}-0.293 \\
(-1.17)\end{array}$ & $\begin{array}{c}-1.394^{* * *} \\
(-7.92)\end{array}$ \\
\hline$S V O L_{O T M}^{C}$ & & & $\begin{array}{c}-0.02^{* * *} \\
(-9.17)\end{array}$ & $\begin{array}{c}-0.005^{* * *} \\
(-6.20)\end{array}$ & $\begin{array}{c}-0.02^{* * *} \\
(-9.13)\end{array}$ & $\begin{array}{c}-0.005^{* * *} \\
(-6.18)\end{array}$ \\
\hline$S V O L_{O T M}^{P}$ & & & $\begin{array}{c}0.01^{* *} \\
(1.96)\end{array}$ & $\begin{array}{c}-0.006^{* * *} \\
(-9.71)\end{array}$ & $\begin{array}{c}0.009^{*} \\
(1.92)\end{array}$ & $\begin{array}{c}-0.006^{* * *} \\
(-9.68)\end{array}$ \\
\hline Adj. $R^{2}$ & 0.002 & 0.003 & 0.042 & 0.031 & 0.042 & 0.032 \\
\hline No. Firms & 4,155 & 4,155 & 4,155 & 4,155 & 4,155 & 4,155 \\
\hline
\end{tabular}


Figure 1: Informed Option Demand and High Information Events. In this figure, we compare the mean values of the cumulative change in the $O M S$ measures before M\&A announcements and days with large return movements as events of high information revelation. We define positive (negative) information large return days as days when the return is above (below) the mean return of all days with positive (negative) returns. As a control group we use the full sample average. The high information date is defined as $t=0$. We plot the cumulative changes of the $O M S^{+}$and $O M S^{-}$measure for the 7 days before high information events. The plot of the cumulative changes for the full sample is marked in red and with triangles. The plot of the cumulative changes for the M\&A dates is marked in green and with dots. The plot of the cumulative changes for the extreme return dates is marked in blue and with diamonds. The upper subfigure plots the different variables for the positive information case. The lower subfigure plots the different variables for the negative information case. The full sample period is January 1996 to December 2009.
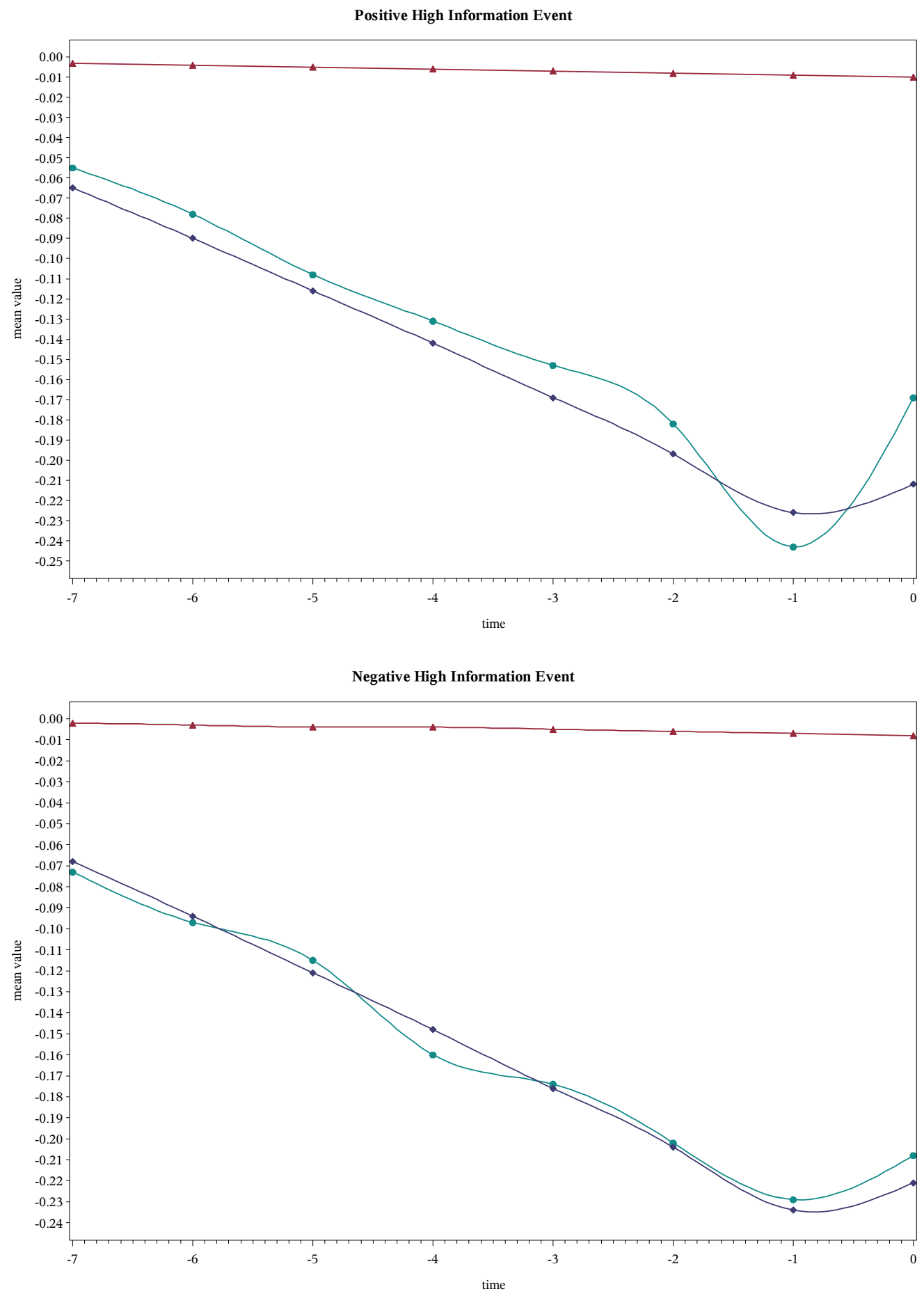
Figure 2: Predictability Horizon of the $O M S$ Measure for Future Stock Returns. In order to obtain the plotted time series, we run daily FMB-regressions of the following form

$$
R E T_{t}=\beta_{0}+\beta_{1} O M S_{t-i}^{+}+\beta_{2} O M S_{t-i}^{2,+}+\beta_{3} O M S_{t-i}^{-}+\beta_{4} O M S_{t-i}^{2,-}+\mathbf{b C}_{\mathbf{t}}+\epsilon_{t},
$$

where $i=\{1,2, \ldots 20\}$. That is, we regress excess stock returns in percent at time $t$ on the $t-i$ lag of the positive and negative information $O M S$ measure $\left(O M S_{t-i}^{j}\right.$ with $\left.j=\{+,-\}\right)$ and the $t-i$ lag of the respective quadratic term $\left(O M S_{t-i}^{2, j}\right)$. The vector of control variables $\left(C_{t}\right)$ is as in the main regression in 22). The left figure plots the slope coefficient of $O M S^{+}$measure. The right figure plots the slope coefficient of $O M S^{-}$measure. The dashed lines are the $95 \%$ confidence intervals. The sample period is January 1996 to December 2009.
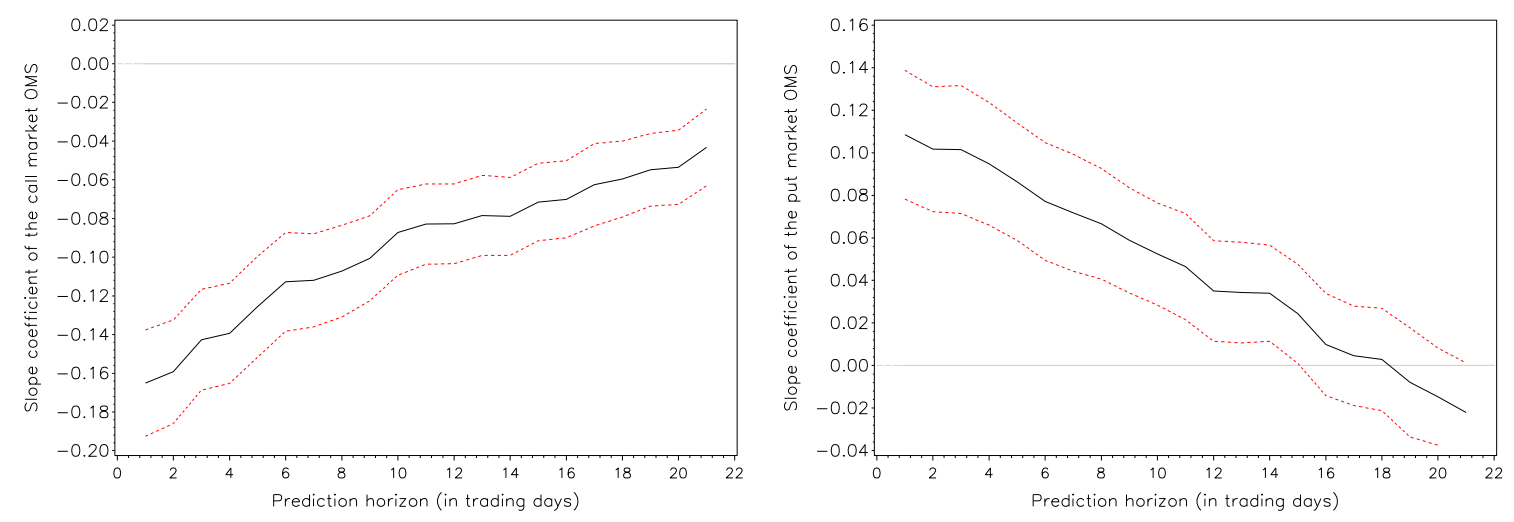


\title{
Appendix 1 Stock Market Control Variables Definitions
}

\author{
Table A1: Stock Market Control Variables Definitions.
}

\begin{tabular}{ll}
\hline Variable & Definition \\
\hline$B M$ & The previous year's end-of-year book equity divided by market equity (cf., Daniel and Titman 2006). \\
$B E T A$ & Monthly market betas estimated as in Easley et al. (2002). \\
$H I$ & The underlying stock's intraday high price. \\
$L O$ & The underlying stock's intraday low price. \\
$M O M$ & 60 days backward looking cumulative return. \\
$P R C$ & The underlying stock's closing price. \\
$R V$ & The underlying's daily realized volatility, $\frac{H I-L O}{P R C} * 10,000$ (cf., Ni et al. 2008). \\
SHROUT & Number of shares outstanding. \\
$S I Z E$ & $\log (P R C * S H R O U T)$ \\
$S T D$ & Square root of the 60 days backward looking average cumulative squared returns.
\end{tabular}

\section{Appendix 2 Controlling for Volatility Informed Trading}

To validate our measure of volatility informed option demand we test, similar to $\mathrm{Ni}$ et al. (2008), whether the $O M S^{\sigma}$ measure predicts the stock individual realized volatility $R V_{t}$ by estimating the following FMB-regression:

$$
R V_{t}=\beta_{0}+\beta_{1} O M S_{t-1}^{\sigma}+\beta_{2} O M S_{t-1}^{\sigma} \cdot E A D_{t}+\mathbf{b}_{\mathbf{1}} \mathbf{D}_{\mathbf{t}}+\mathbf{b}_{\mathbf{2}} \mathbf{C}_{\mathbf{t}}+\epsilon_{t}
$$

with

$$
\mathbf{D}_{\mathbf{t}}=\left[\begin{array}{llll}
O M S_{t-1}^{+} & O M S_{t-1}^{+} \cdot E A D_{t} & O M S_{t-1}^{-} & O M S_{t-1}^{-} \cdot E A D_{t}
\end{array}\right]
$$

as the vector of variables that control for directional informed trading. $\mathbf{C}_{\mathbf{t}}$ is again a set of control variables, which additionally includes current and lagged $R V$ to control for information in current and lagged $R V$. The corresponding coefficient vectors are $\mathbf{b}_{\mathbf{1}}$ for $\mathbf{D}_{\mathbf{t}}$ and $\mathbf{b}_{\mathbf{2}}$ for $\mathbf{C}_{\mathbf{t}}$. $E A D_{t}$ is one if $t$ is an earnings announcement date $(E A D)$ for the respective stock and is zero otherwise.

Previous literature shows stock return volatility is likely to increase after earnings announcements (e.g., Ni et al. 2008, Beaver 1968) and the insight that volatility informed investors are more likely to trade prior to earnings announcement dates (see Ni et al. 2008, Sarkar and Schwartz 2009), we expect a positive slope coefficient for $O M S^{\sigma} \cdot E A D_{t}$, i.e., $\beta_{2}>0$ and $\left(\beta_{2}+\beta_{1}\right)>0$. For the $O M S^{\sigma}$ measure it is ambiguous, which coefficient to expect because high and low volatility bets could result in an increase in open interest of both contract types. However, we include the variable into the regression in order to control for non- $E A D$ times. A significant positive coefficient for the $O M S^{\sigma}$ measure indicates that on average a large increase in ATM straddle trading is associated with an increasing future volatility.

Since $E A D s$ are public knowledge and markets tend to be largely driven by diverse beliefs prior to EADs (cf., Sarkar and Schwartz 2009, Choy and Wei 2012), we expect the impact of directional informed trading before announcement dates to be negligible. Thus, for the directional $O M S$ measure we conjecture an insignificant coefficient for the $E A D$ interacted $O M S$ measure. For the non- $E A D$ interacted $O M S$ measures, we expect, if at all, negative 
signs for the coefficients, implying that decreasing $O M S^{+}$and $O M S^{-}$indicate for both market sides an increase in the future realized stock return volatility. This is intuitive since the future price discovery in the stock market is most likely associated with an increase in the return volatility, no matter whether the stock returns increase or decrease.

Table A2 reports the results for the volatility predictive regressions.

We express the realized volatility in basis points, therefore the coefficients indicate daily basis point changes after e.g. the $O M S$ measure drops from zero to minus one. To save space we omit the regression results of the controls. In row (I) the coefficients are significant at the $1 \%$ level. The coefficient for the $O M S^{\sigma}$ is not straight forward interpretable due to the fact that ATM straddle bets on increasing as well as decreasing volatility would both increase the open interest in the respective call and put option pairs. However, the $E A D$ interacted $O M S^{\sigma}$ coefficient is directly interpretable since earnings announcements are usually associated with an increase in return volatility. The coefficient of the $E A D$ interacted $O M S^{\sigma}$ measure is as expected positive and $\beta_{2}+\beta_{1}>0$, implying that an excess demand in call and put option ATM straddle pairs conditional on an $E A D$ strongly indicates trading on increasing future volatilities. This corroborates our expectations and validates $O M S^{\sigma}$ as indicator of volatility trading.

In row (II) we add $O M S^{+}$and $O M S^{-}$in order to verify the robustness of the results for the $O M S^{\sigma}$ measure. Furthermore, this specification helps to provide support to the hypothesis that the $O M S^{+}$and $O M S^{-}$measures are associated with directional information trading. In particular, we are interested in the coefficient of the $O M S$ measures around $E A D s$. The results show that indeed the EAD interacted directional $O M S$ measures exhibit neither for the positive nor for the negative information case a significant coefficient. For the entire time series of the realized volatility, a lower directional $O M S$ measure implies for both market sides increases in the future realized stock return volatility, which is in line with our expectations. 


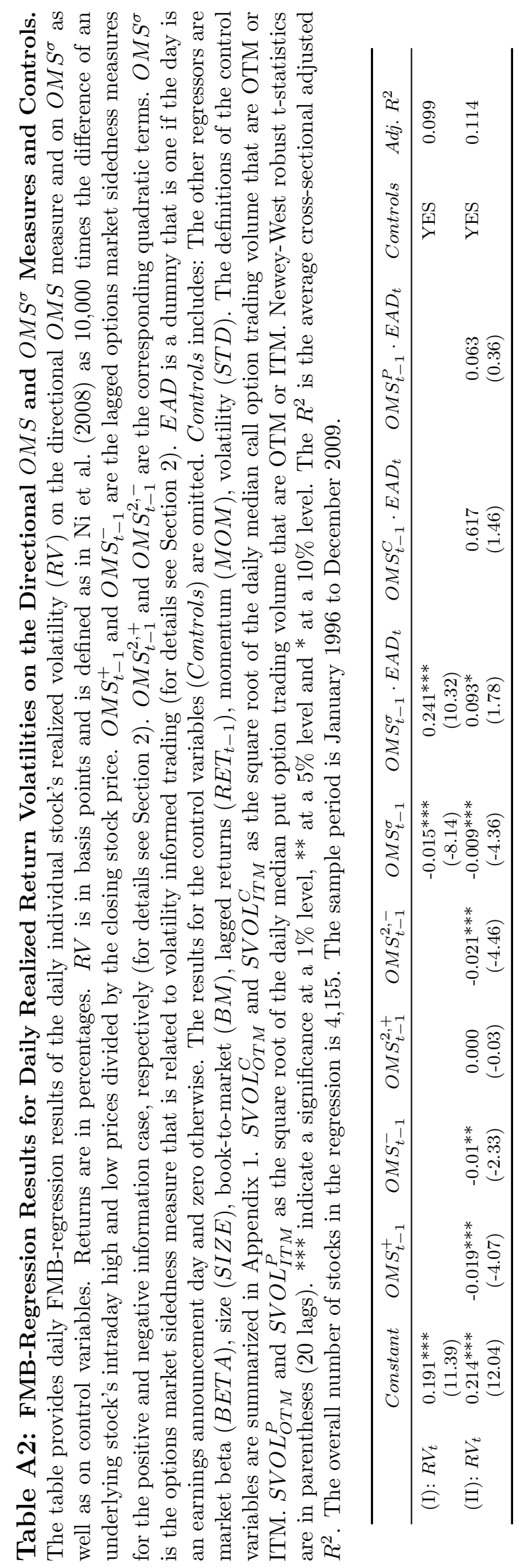




\section{Appendix 3 Information Flows between $O M S$ and Stock Returns}

To investigate the information flows between the options market sidedness measures and stock returns we test in a trivariate VAR system whether stock price changes Granger cause options market one- or two-sidedness and vice versa.

For this purpose, we model the following $\operatorname{VAR}(5)$ system 50 ;

$$
\left[\begin{array}{c}
R E T_{t} \\
O M S_{t}^{+} \\
O M S_{t}^{-}
\end{array}\right]=\mathbf{c}+\sum_{p=1}^{5} \mathbf{B}_{p}\left[\begin{array}{c}
R E T_{t-p} \\
O M S_{t-p}^{+} \\
O M S_{t-p}^{-}
\end{array}\right]+\varepsilon_{t}
$$

with $\mathbf{B}_{p}$ as a $(3 \times 3)$ the coefficient matrix.

The VAR can be reformulated as an infinite vector moving average model, that is VMA $(\infty)$ :

$$
\mathbf{Y}_{t}=\boldsymbol{\mu}+\varepsilon_{t}+\Psi_{1} \varepsilon_{t-1}+\Psi_{2} \varepsilon_{t-2}+\ldots
$$

where $\boldsymbol{\Psi}_{1}, \boldsymbol{\Psi}_{2}, \ldots$ denote the MA coefficients. From (7) we compute impulse response functions that give the response of the system variables to a one unit shock in one variable of the VAR. We use the cumulative values of the impulse response function to measure the total impact of a shock for up to 25 days. The resulting cumulative impulse response functions for the relations of interest are displayed in Figure 3.

A one unit negative change in the innovation of the $\mathrm{OMS}^{+}$, i.e., an increase in options market one-sidedness due to positive information, results in an increase of returns (left upper panel in Figure 3). Analogously, the right upper panel in Figure 3 illustrates that a negative shock from the $O M S^{-}$measure on stock returns results in a decrease of stock returns. The figures indicate that it takes several days until the impact of the shock in the $O M S$ measure on returns is fully incorporated. Hence, private information in options markets at time $t$ is only gradually incorporated into prices in $t+1$ and throughout the following days. The results further corroborate our hypothesis that more one-sided markets indicate asymmetric information in the options markets and that indeed markets are not efficient and directional information moves with a considerable lag from options to stock markets.

Furthermore, the effects of return related shocks to the options market sidedness measures provide support to the notion that stock return news trigger joint demand shifts in the options market and make it more two-sided. Positive return innovations in the stock market result in an increase in $\mathrm{OMS}^{+}$, reflecting an increase in options market symmetry simultaneously to the public news arrival and price readjustment in stock markets (left lower panel in Figure 3). Similarly, negative return shocks have a positive impact on $O M S^{-}$, which analogously to the positive information case reflects an increase in options market symmetry (right lower panel in Figure 3).

\footnotetext{
50 We tested a large range of different lag sizes and do not find substantial qualitative differences between the specifications. Thus, we choose one trading week as a time window.
} 
Figure 3: Cumulative Impulse Response Function. The figure shows cumulative impulse response functions using a horizon of 25 days and the $\operatorname{VAR}(5)$ specification:

$$
\left[\begin{array}{c}
R E T_{t} \\
O M S_{t}^{+} \\
O M S_{t}^{-}
\end{array}\right]=\mathbf{c}+\sum_{p=1}^{5} \mathbf{B}_{p}\left[\begin{array}{c}
R E T_{t-p} \\
O M S_{t-p}^{+} \\
O M S_{t-p}^{-}
\end{array}\right]+\varepsilon_{t},
$$

with $\mathbf{B}_{p}$ as a $(3 \times 3)$ coefficient matrix. The upper left panel depicts the cumulative impulse response function (CIR) for a negative one unit change in the innovation of $O M S^{+}$on stock returns. The upper right panel depicts the CIR function for a negative one unit change in the innovation of $O M S^{-}$on stock returns. The lower left panel depicts the CIR function for a positive one unit change in the innovation of the stock returns on $O M S^{+}$. The lower right panel depicts the CIR function for a negative one unit change in the innovation of the stock returns on $O M S^{-}$. The sample period for the VAR estimation is January 1996 to December 2009. The dashed lines represent $95 \%$ confidence bounds.
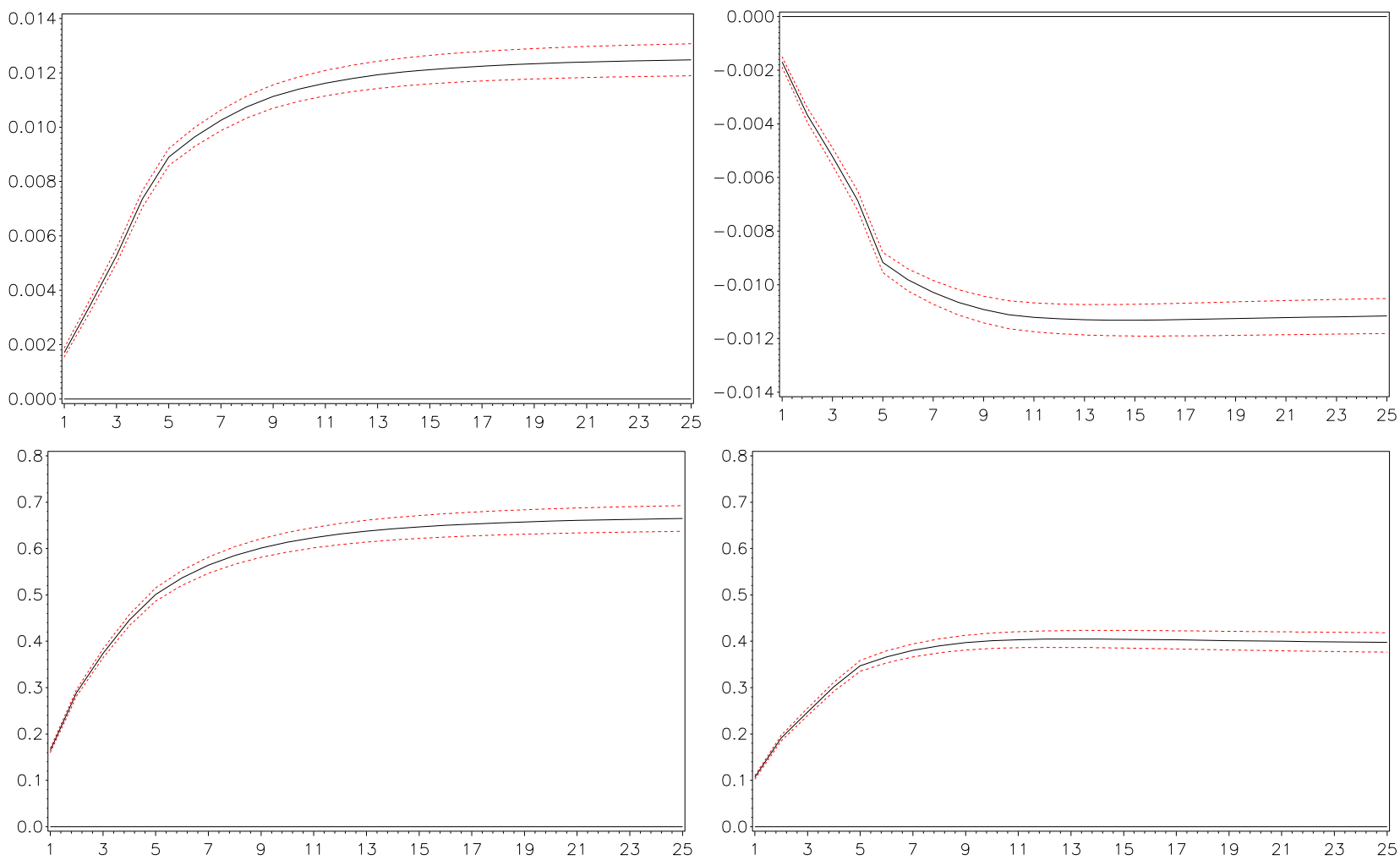


\section{Appendix 4 Additional Trading Strategy Results}

As a first robustness check, we increase the trading threshold to study how sensitive our strategy returns are to increasing the threshold. More specifically, we choose the $25 \%$ quantile of $O M S^{+}(0.11)$ and $O M S^{-}(0.16)$. In each trading round we are on average invested in option contracts of 1462 different stocks associated with positive $O M S$ trading signals and in option contracts for 1553 different stocks associated with negative signals depending on the strategy type. In Table A3 we report the trading strategy results.

In summary, the returns are lower than those for the $O M S=0$ threshold but in general the results are robust to increasing the trading threshold to the $25 \%$ quantile. The decrease in returns is to be expected since we trade on a relatively larger fraction of weaker informative or relatively uninformative signals. On the other hand, it also shows that the results in the main text for the $O M S=0$ threshold are not just driven by some outliers that are averaged out once we increase the window of possible trading thresholds. 


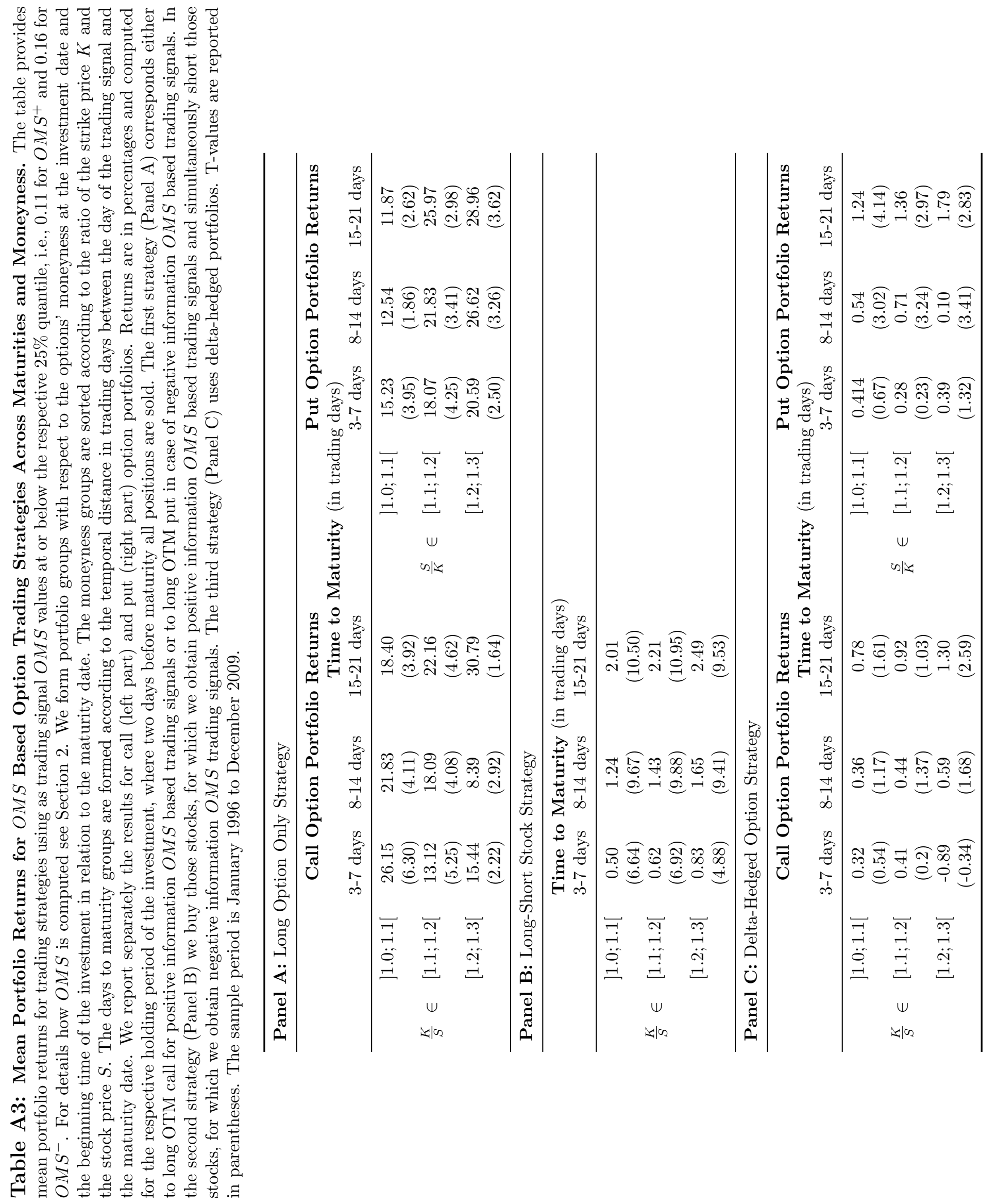


Next, we introduce transaction costs to our benchmark case, i.e., the trading threshold of $O M S^{+}$or $O M S^{-}$being 0 . Transaction costs for trading options are known to be particularly large for OTM options and are significantly larger than those for stocks. For instance, Ni (2010) and McKeon (2013) show that option trading returns for call options are likely to be negative for the average investor. However, for a more sophisticated investor with directional information and in particular also on the put market side, this might be different. Hence, it is interesting to test whether the substantial returns to the $O M S$ based option trading strategies are relatively robust to accounting for transaction costs.

However, there are some caveats to keep in mind when interpreting these results. First, similar to $\mathrm{Ni}$ (2010) and McKeon (2013) we have no data on the actual trading accounts and hence on the actual trading costs; we can only generally account for transaction costs based on the option spread. Hence, these results are to be treated with caution since for instance for institutional investors (which are also most likely to be the informed traders) the transaction costs are much lower than what we assume here while for a retail investor they could also be larger. Second, our trading strategy takes the perspective of an investor, who tries to follow options market one-sidedness and is can only trade at least one day (or potentially also several days) after the informed traders exert a one-sided demand pressure on market makers. As we have seen in Section 7 informed trading increases future spreads. Hence, in some situations the spreads might be significantly smaller for the informed investor who as a consequence will be much less affected by transaction costs than an uninformed trader who tries to follow the information that market one-sidedness reveals. Third, one more caveat for interpreting these results is that our trading strategy does not incorporate the spread size as a side condition, which is likely to be the case at least for more sophisticated traders that often use trade algorithms that optimize transaction costs.

Table A4 reports the results for rerunning the option trading strategies for the $O M S=0$ threshold accounting for transaction costs that amount to 25\% (Panel A) and 50\% (Panel B).

The results show that even after accounting for substantial transaction costs, trading on $O M S$ still yields substantial returns. However, there is obviously a trade-off between taking on leverage and the larger spreads that are implied by OTM options. Despite the fact that OTM options are the most frequently traded option type, spreads increase substantially the further the option is OTM. Therefore for some of the trading strategy results, the profits become negative. However, for relatively longer investment periods and also for closer to the money options, the returns are relatively robust to incorporating these hypothetical transaction costs. Put options returns are also more robust to transaction costs.

We would expect that choosing a more extreme (in terms of market one-sidedness) trading threshold for $O M S$ is also likely to improve the spread adjusted trading strategy returns. To demonstrate the effect of lowering the trading threshold value of $O M S$ we report below trading strategy results using a threshold of $O M S^{+}$or $O M S^{-}$being -0.2. Using this trading threshold, we invest still into a fairly large amount of option contracts for different underlyings, that is option contracts for 147 different company stocks on average per trading round for positive information trading and option contracts on 139 different stocks on average per trading round for negative information trading.

Table A5 summarizes the results for rerunning the option trading strategies applying a trading threshold of $O M S=-0.2$ and accounting for transaction costs that amount to $25 \%$ 
(Panel A) and 50\% (Panel B).

The results highlight that the more informative the trading signal that we use, the more robust is the trading strategy to transaction costs. The put option results remain all qualitatively unchanged even when accounting for transaction costs amounting to $50 \%$. The results for the call options are also for almost all option types and investment durations positive and significant, only for relatively far out of the money options with very short times to maturity, the profits become insignificantly different from zero on average or are negative. 


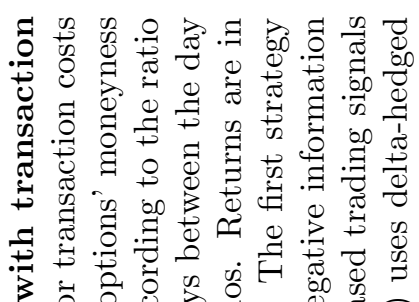

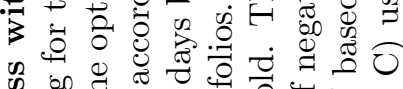

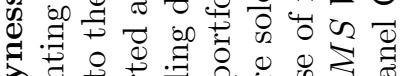

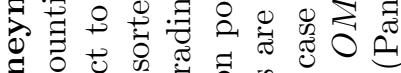

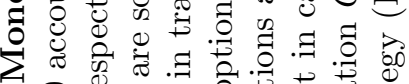

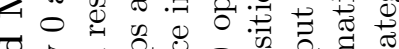
च o 8 के .

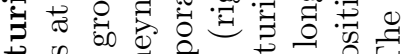
䒕

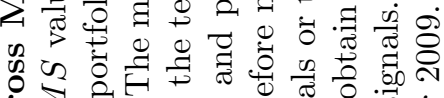
¿

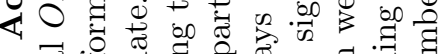

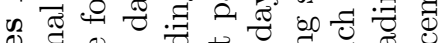

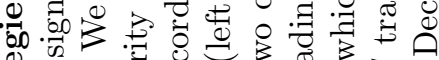

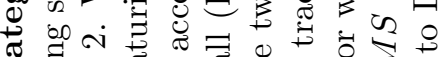
部 so $\begin{aligned} & \pm \\ & 0\end{aligned}$

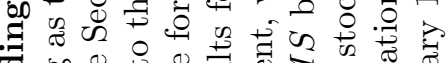
శ.

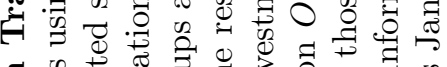

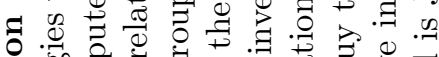

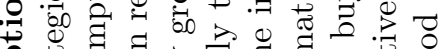
คै

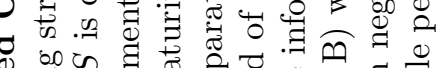

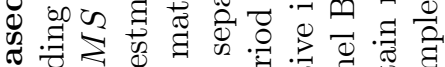
ต

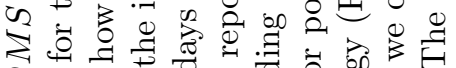
0 을 낭

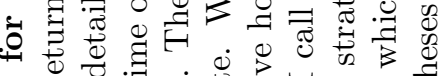

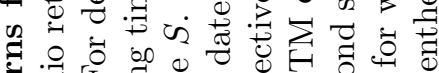

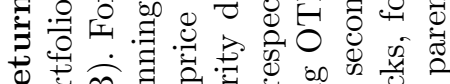

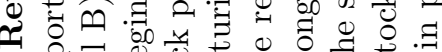

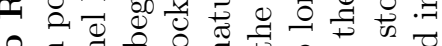

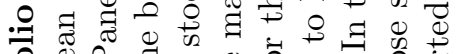

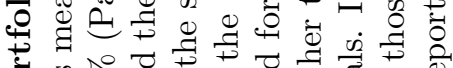

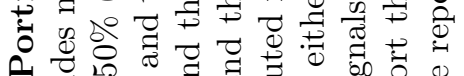

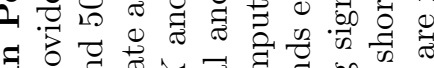

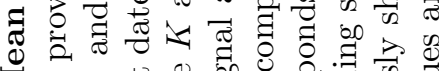

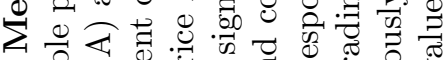

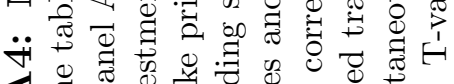

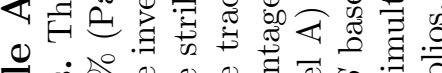

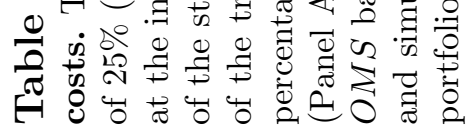




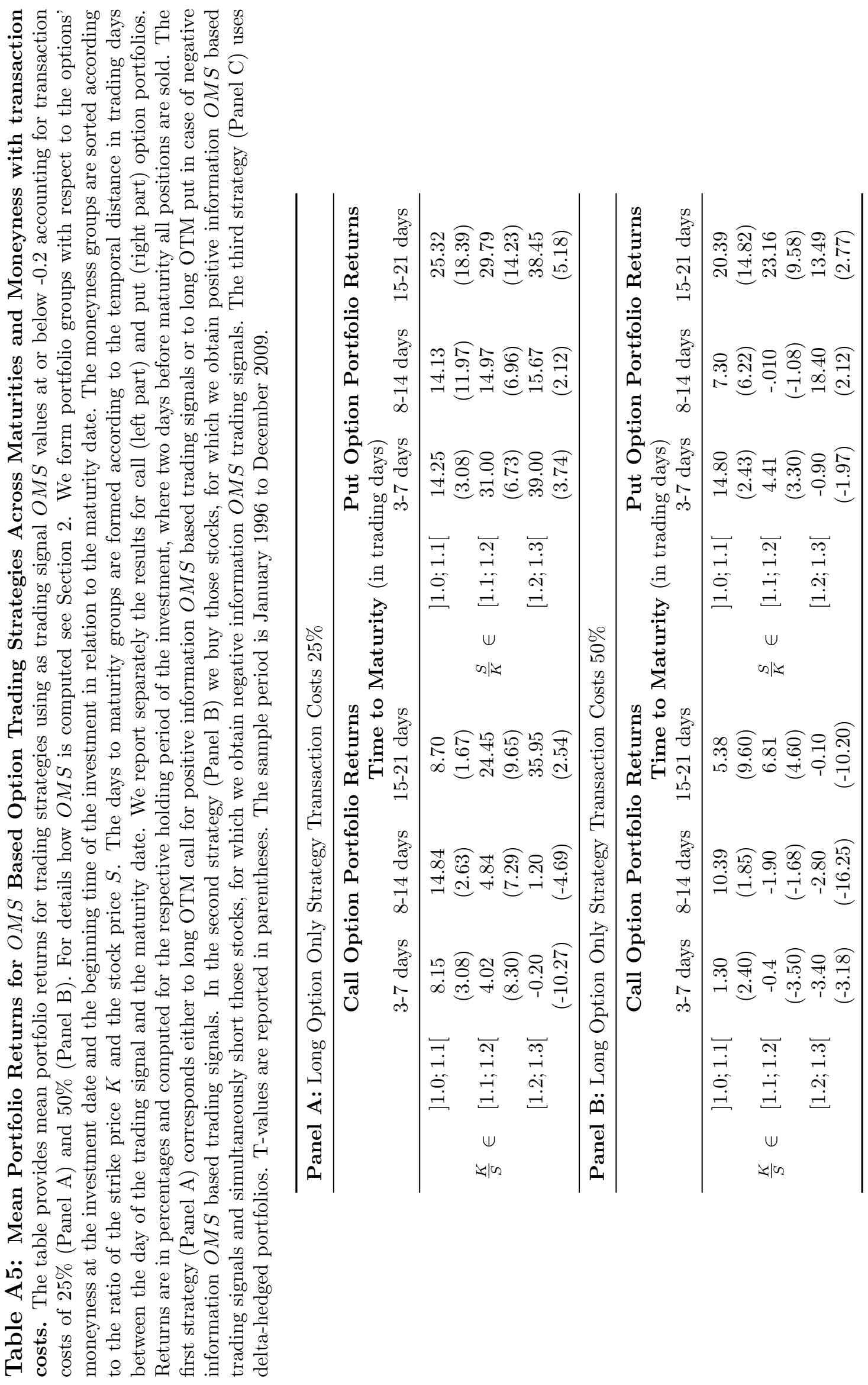


In a second set of trading strategies, we choose as trading signals decreases in the $O M S^{+}$ and $O M S^{-}$measures that are larger than the respective average decrease in $O M S$ between date $t-2$ and $t-1$ before a high information event (see Section 3.2), i.e., -0.055 for $O M S^{+}$ and -0.07 for $O M S^{-}$.

In Table A6 we report mean returns of the portfolios that are formed in each trading round (roughly one month) for each trading strategy, i.e., long call, long put, long-short stock or delta-hedged, respectively. On average in each trading round we are invested in option contracts of 941 different stocks due to positive $O M S$ based trading signals and in option contracts for 992 different stocks due to negative signals depending on the strategy type. 51

The results for the simple long put option strategy in the right part of Panel A show that farther OTM options provide on average for each trading round higher portfolio returns. The average portfolio returns for the different maturity and moneyness groups range between $9.5 \%$ and $36 \%$ per trading round. The left part of Panel A shows the profitability of $O M S$ based OTM long call option strategies. The profits across all maturity and moneyness groups range between $6 \%$ and $22 \%$ per trading round. The t-statistics in parentheses are significant at a $1 \%$ level in almost all cases.

Panel B reports the results for the investment strategy that goes long in those stocks, for which we obtain a positive $O M S$ based trading signal, and that sells those stocks, for which we obtain a negative information signal from $O M S^{-}$. As in the above, we use stock returns that are orthogonalized with respect to the Fama-French and Carhart factors. All returns across maturities and moneyness groups are significantly larger than zero, increase with moneyness and with the time to maturity and range between $0.47 \%$ and $2.24 \%$ per trading round.

The economic significance of the options market sidedness hypothesis is further corroborated by the results for the delta-hedged strategy in Panel C. Most of the delta-hedged returns are statistically not different from zero and only some are slightly and significantly larger than zero. This supports the view that it is directional information rather than a higher moment risk compensation that shows up in the returns of the above strategies.

\footnotetext{
${ }^{51}$ For very extreme values of $\triangle O M S$ (e.g., -0.2 ) these numbers go down below 50 and the trading strategies
} yield very high positive returns but are also more volatile. 


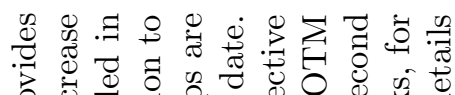

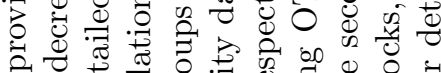

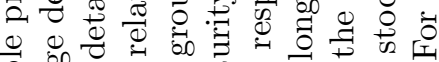

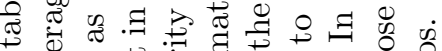

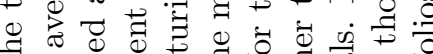

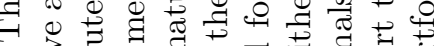

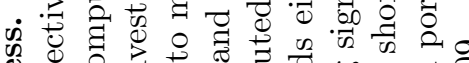
⿹

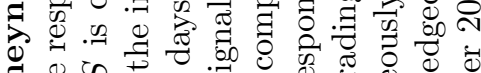
ఫ $\sum \approx$

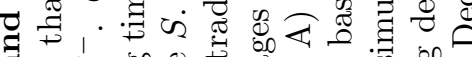
ส थ

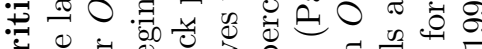

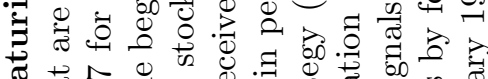
党

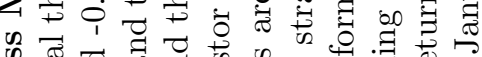

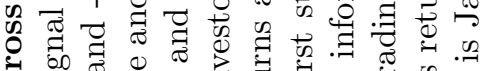

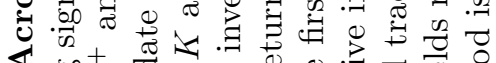

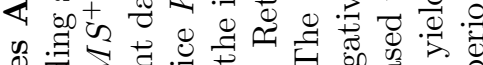
कृ

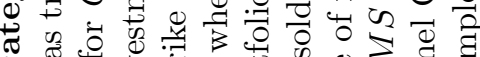

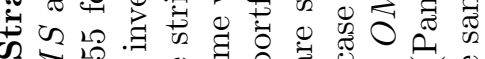

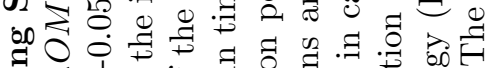

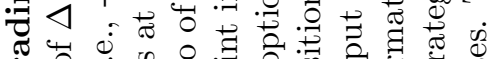
क्ष

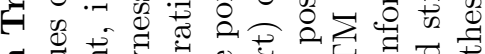

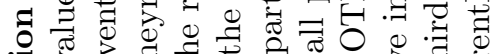
苗 菊. is no 3 उ

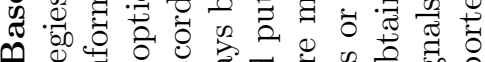
9 यू: $\zeta \infty$ s

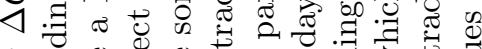

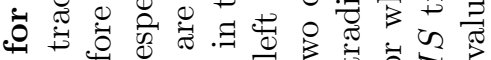
\% : : 0 :

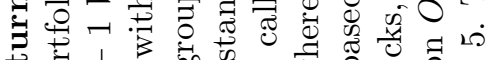

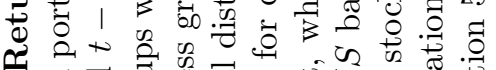

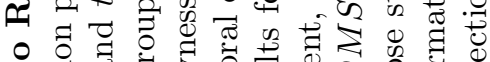

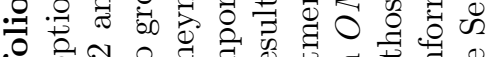

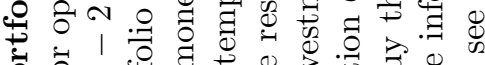

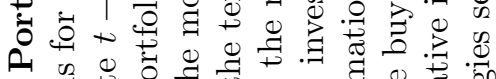

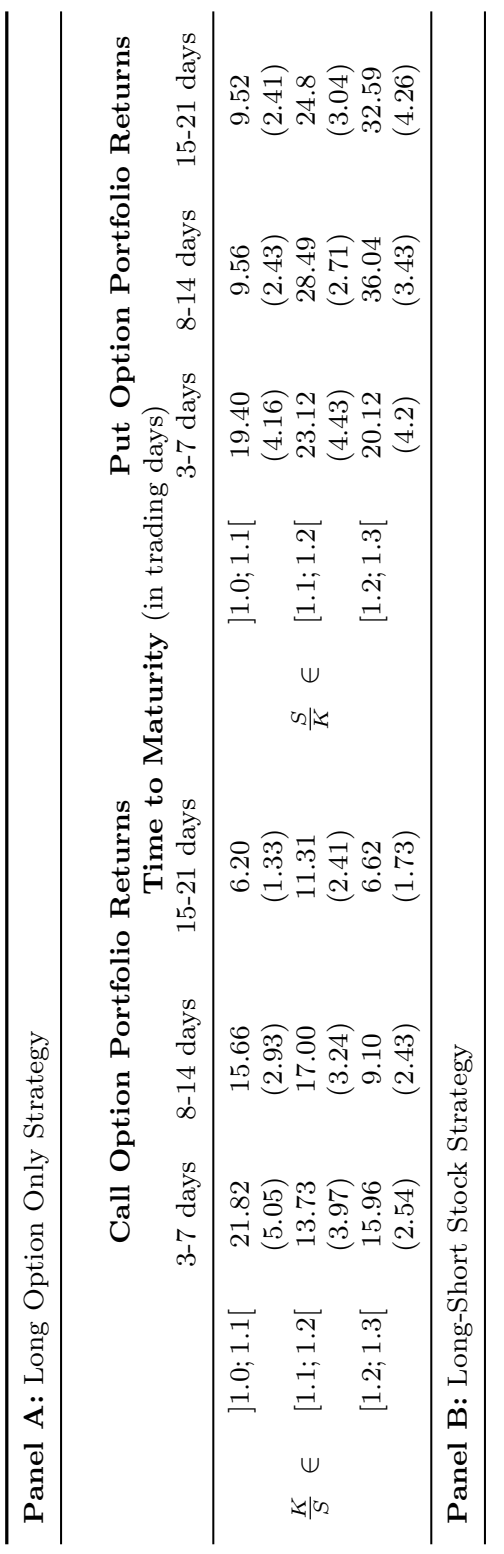

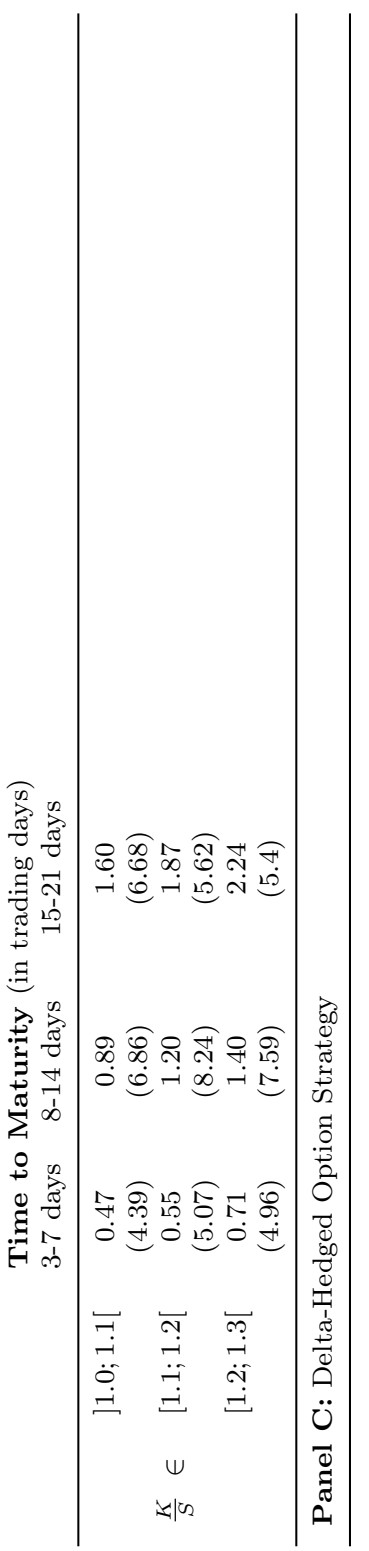

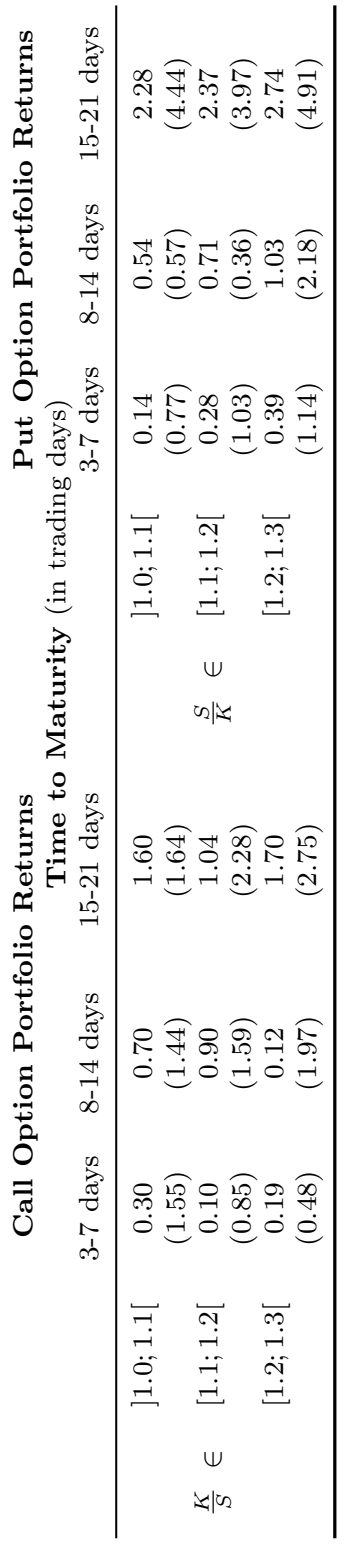

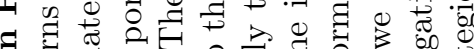
đั

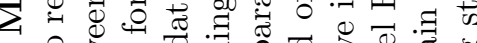

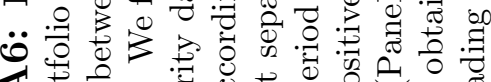

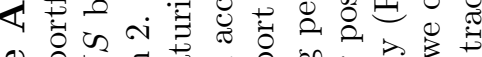
응

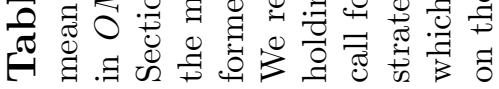

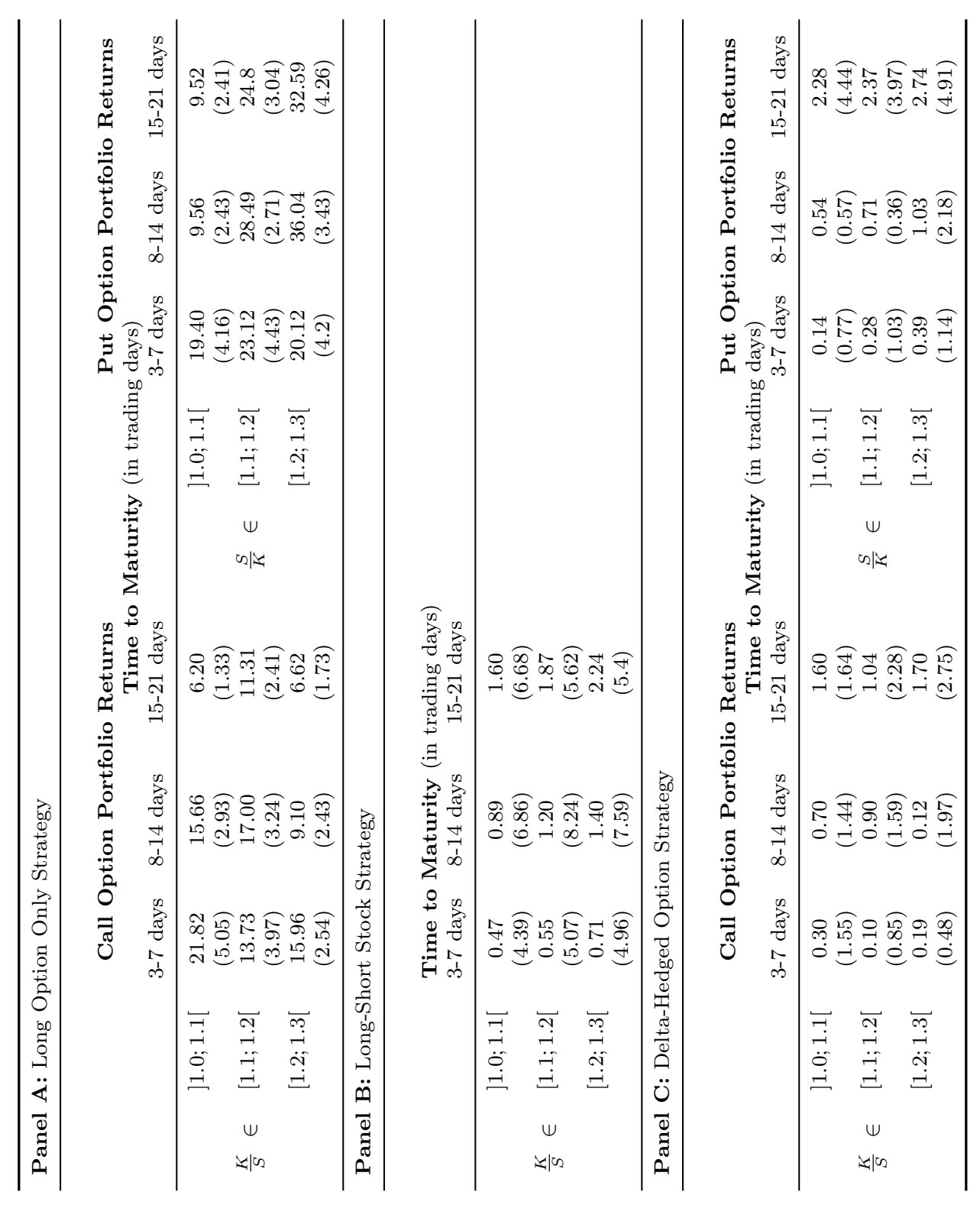


To test whether options market sidedness captures more that just momentum, we rerun the trading strategies using three different approaches. We first sort the stocks in each month $m$ according to their average (m-2:m-12)-month stock return and then use the top quintile as the winner portfolio and the bottom quintile as the loser portfolio ${ }^{52}$ In our first testing approach, we aim at shutting off momentum signals as major explanation of the trading strategy returns. Therefore, we trade on positive signals only within the subsample of stocks in the loser portfolio, i.e., those stocks that we would sell in a momentum strategy. Additionally, we generate $O M S$ based negative information signals and trade on them by buying puts or shorting stocks only within the winner portfolio, i.e., the portfolio of stock that we would buy in a momentum strategy. Intuitively, we restrict our positive signal trading to the sample, where we would expect the least positive momentum and the negative signal trading to the sample, where we would expect the least negative momentum. In these "reversed-momentum" subsamples we would expect substantially worse or even economically insignificant results for our trading strategies if the options market sidedness measure mainly picks-up momentum signals. The results are reported in A7. In summary, the analysis shows that the returns that we generate by selecting investments for "momentum" or "reversed-momentum" portfolios, conditioning on the $O M S$ measures, are on average higher for those portfolios that a traditional momentum trader would not expect to perform well. This corroborates that options market sidedness captures information in option trading that is clearly different from pure momentum signals and that also helps to identify (private) directional signals for securities that a simple momentum strategy would neglect.

\footnotetext{
${ }^{52}$ In unreported tests we also exclude the month of January or December or both months in order to control for possible effects from window dressing and the January effect. Our results remain qualitatively unchanged, however for some moneyness-maturity groups the profits are lower.
} 


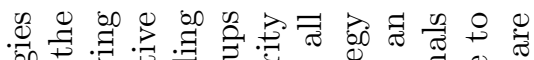

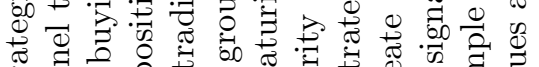

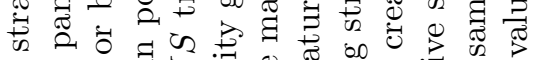

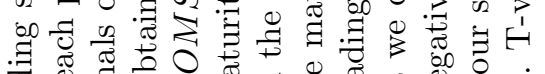

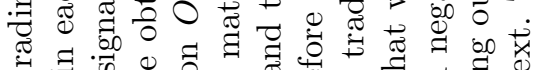

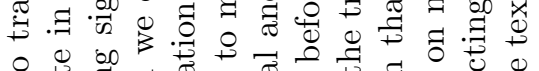

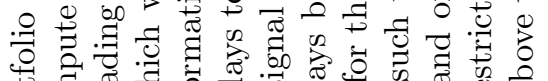

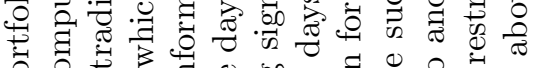

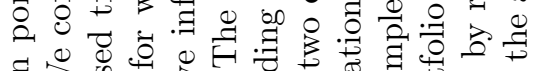

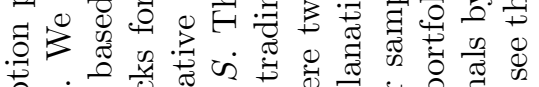

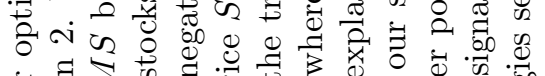

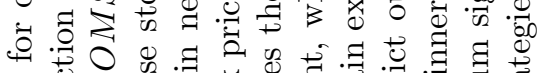

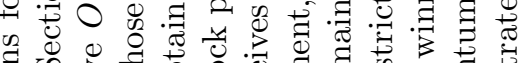
记.

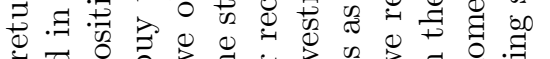

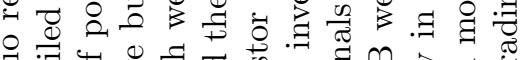
윽 퓽

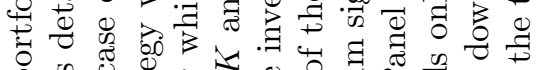

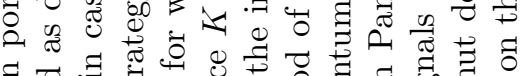

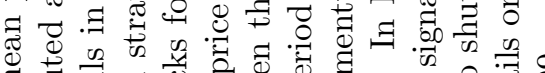
घ क

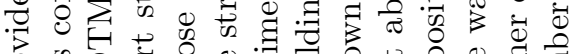

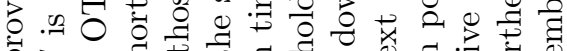
讪 00 क स

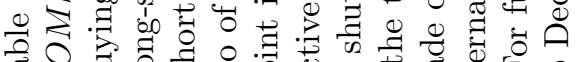

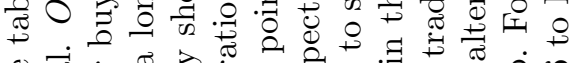

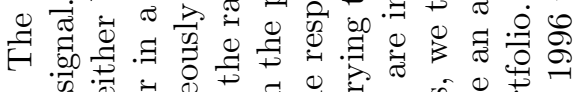
.

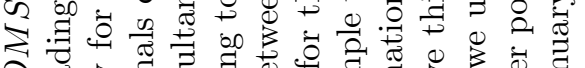

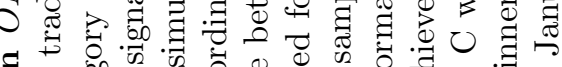
a on 0

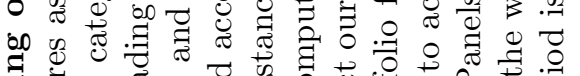

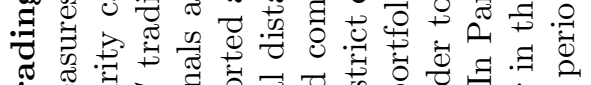

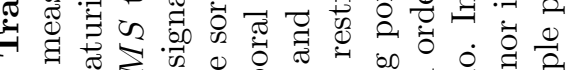

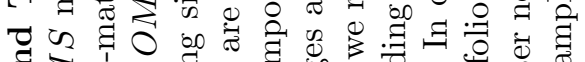
ส

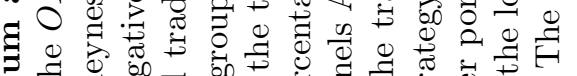

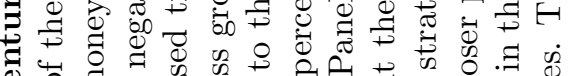

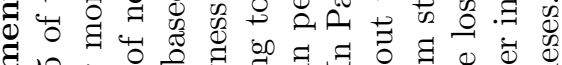

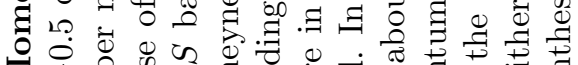

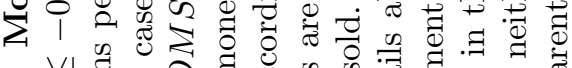

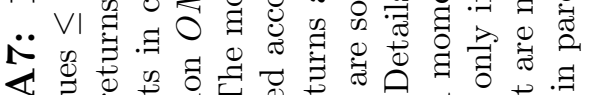

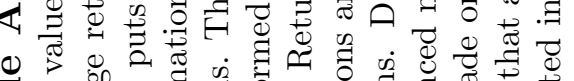

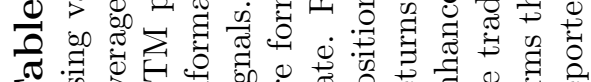

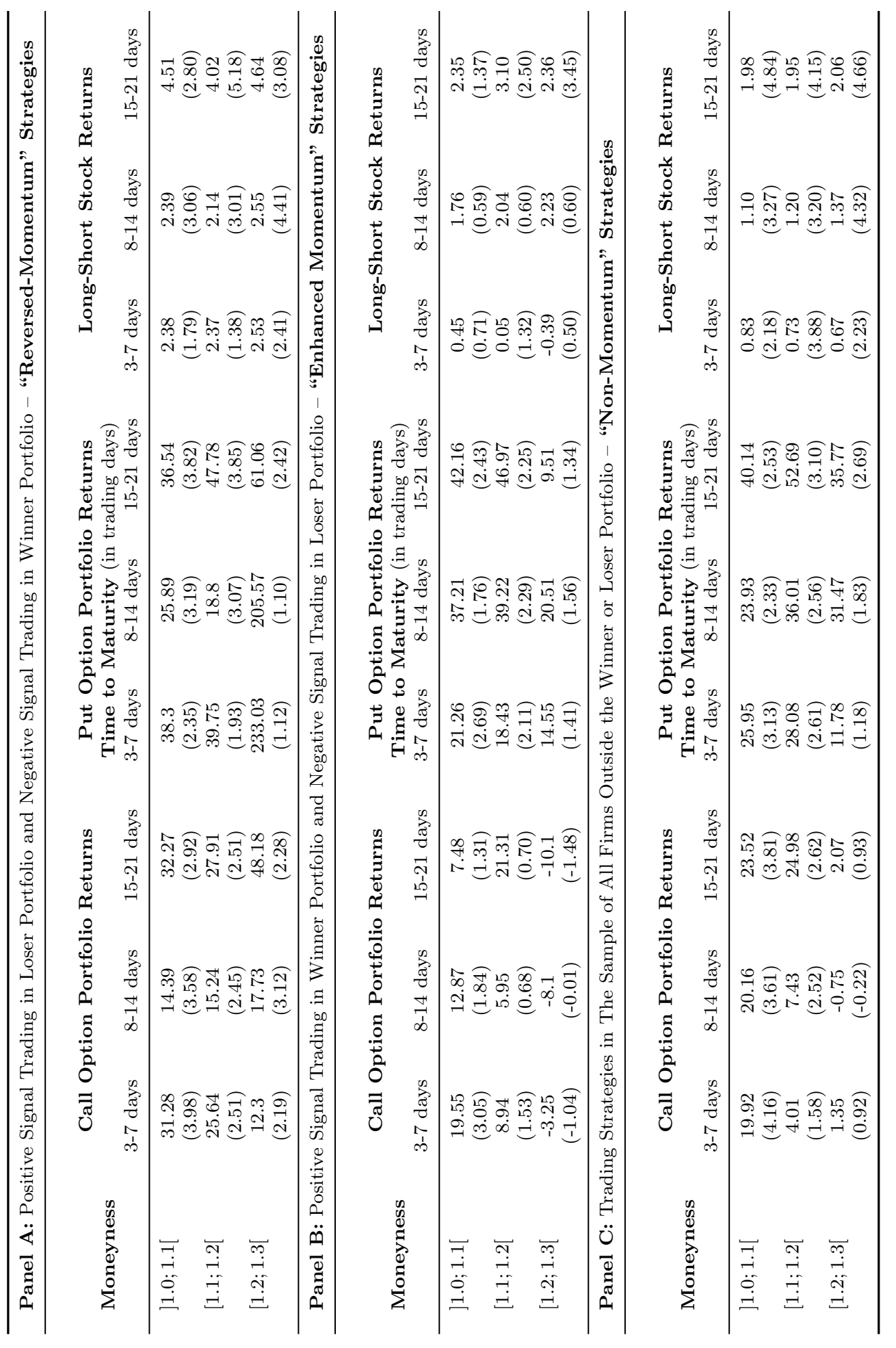

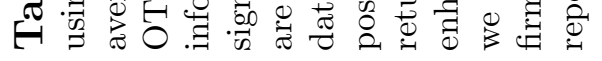

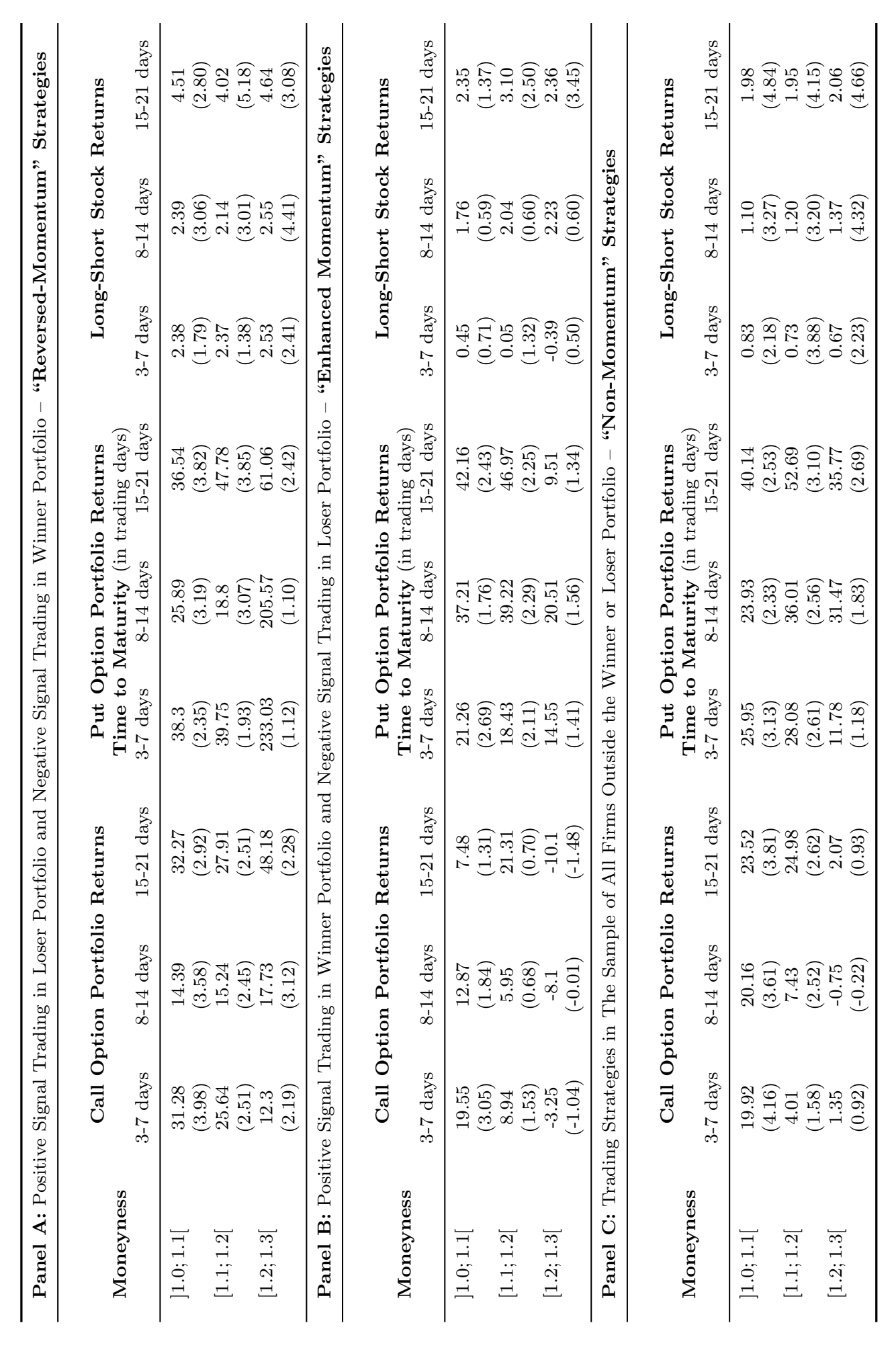

